Arqueología y Sociedad,

№ 20, 2009

\title{
Las divinidades de la Cultura MochicA*
}

\author{
Bärbel Lieske**
}

\section{Resumen}

El presente trabajo pretende hacer un compendio de las representaciones del panteón mochica. El propósito era reconocer a las divinidades con sus características diferenciables, agruparlas, darles un nombre y presentarlas en imágenes seleccionadas, acompañadas de una descripción breve. Hasta el momento no se ha ofrecido un catálogo sistemático de esta naturaleza. El trabajo quiere formar la base para el manejo de las representaciones numinosas en el arte mochica. Las imágenes tratan de mostrar la variedad de las divinidades y quiere ayudar en la identificación de ellas. Ojalá que induzca a trabajos posteriores y al debate.

\section{Palabras clave}

Divinidades, descripción comparativa, atributos, apariencia combinatoria.

\begin{abstract}
The present work tries to do a compendium of the representations of the pantheon mochica. The intention was to recognize the divinities with his distinguishable characteristics, to group them, to name them and to present them in chosen images, accompanied by a brief description. Until now a systematical catalog of this nature has not been offered. The work wants to form the base for the handling of the representations numinosas in the art mochica. The images try to show the variety of the divinities and he wants to help in the identification of them. I hope that it induces to later works and to the debate.
\end{abstract}

\section{Keywords}

Divinities, comparative description, attributes, combinatorial appearance.

* Título del original en alemán Göttergestalten der altperuanischen Moche-Kultur. Traducción J. Golte

** Freie Universität Berlin. 


\section{INTRODUCCIÓN}

La cultura Mochica es una de las culturas regionales tempranas del Perú. Florece del siglo I hasta el siglo VI de Nuestra Era. Los asentamientos moches se encuentran en la costa norte peruana a lo largo de los valles de los ríos La Leche, Lambayeque, Zaña, Jequetepeque, Chicama, Moche, Virú, Chao, Santa y Nepeña. El desierto norteño abarca una franja de hasta cincuenta kilómetros de ancho entre el mar y las estribaciones de los Andes. En este desierto los ríos que nacen en la vertiente occidental de la cordillera forman oasis fértiles. Una red de acequias les daba a los moches la posibilidad de ampliar continuamente sus campos agrícolas.

Al lado de construcciones monumentales de adobe, son ante todo los ceramios hallados por cientos de miles en las tumbas los que nos proporcionan una imagen de su cultura. Especialmente las vasijas escultóricas, y otras en bajorrelieve y pintadas son de importancia. Estos ceramios nos ofrecen una visión de los imaginarios mochica. Dioses, humanos, animales, detalles de construcciones y del paisaje son mostrados en muchas variaciones. En imágenes escénicas se nos cuenta de batallas, de competencias, de la cacería, del mundo de los muertos, y de acontecimientos rituales y míticos.

He tratado de presentar los seres divinos que actúan en este mundo de imágenes en un primer trabajo publicado en alemán (Lieske 1992). Mis trabajos posteriores y la publicación de nuevas imágenes me han hecho desarrollar nuevos puntos de vista y criterios de clasificación.

Para los nombres de las divinidades, tomando como inspiración a la obra de Paul Schellhas, que introdujo en 1897 en su trabajo sobre las divinidades mayas la clasificación alfabética, he utilizado las letras neutras del alfabeto. Como se amplió el número de seres divinos de 20 en el primer trabajo ya citado a 37 en el presente, tuve que desarrollar un esquema alfabético ampliado. Para ello se hizo una agrupación previa de los dioses en cinco categorías:

Se diferenció

1. Las divinidades antropomorfas,

2. Las divinidades zoomorfas,

3. Las divinidades híbridas,

4. Las divinidades fitomorfas,

5. Las divinidades en forma de objetos.

Los nuevos nombres utilizan dos letras separadas por un guión. La primera, minúscula, se refiere a la clase de seres, y la segunda, mayúscula, se refiere a la secuencia en los personajes de la clase. Por ejemplo, la divinidad z-E es una divinidad zoomorfa con la posición E en la secuencia. Un número puesto detrás del nombre, por ejemplo, a-F(1) se refiere a una transformación del personaje a-F. Para ofrecer algo de plasticidad se le añade una explicación breve en palabras, por ejemplo h-A es descrito como «el monstruo con el caracol strombus».

Para ofrecer una descripción comparativa de las figuras de las divinidades presentadas se utiliza un esquema de descripción. Este incluye cuatro puntos principales: rasgos antropomorfos, rasgos zoomorfos, atributos en general y requisitos. Los atributos humanos caracterizan la presentación de la cabeza, el cuerpo, las extremidades, el tocado, ropa y adornos. Los atributos de animales presentan la cabeza, el cuerpo y las extremidades. Atributos en general se refieren a añadidos característicos. Requisitos se refieren a instrumentos que son característicos del ser. No se trata en este trabajo otros criterios como las acciones y el ámbito en el cual aparecen los seres divinos.

Particular para las divinidades moches es su apariencia combinatoria. Por ejemplo, es característica de todas las divinidades, independiente de su forma específica, una boca de felino. Esta característica animal compartida por todas hay que entenderla como un indicador de su naturaleza divina. Especialmente en las esculturas la forma modelada de estas fauces divinas resulta impresionante. La boca es anchada y muestra 
en las comisuras dos dientes felínicos alargados. Esta característica impresiona al espectador y causa un aire amenazante.

La apariencia combinatoria puede ser descrita de la siguiente manera

1. Divinidades antropomorfas: cabeza humana con fauces felínicas, cuerpo humano, extremidades humanas, vestimenta humana.

2. Divinidades zoomorfas: cabeza específica de especie animal con fauces felínicas, cuerpo humaniforme, mayormente extremidades humaniformes, vestimenta humana, elementos específicos de especie de animal como alas o cola.

3. Divinidades híbridas: divinidades compuestas de rasgos de animal y también algunos rasgos humaniformes, mayormente cabeza de animal rapaz, cuerpo de animal, algunas veces también cuerpo humano con vestimenta humana, extremidades animales, algunas veces también extremidades humanas.

4. Divinidades fitomorfas: cabeza humana, algunas veces con fauces felínicas, cuerpo específico de planta, extremidades humanas, partes de vestimenta humana.

5. Divinidades en forma de objeto: cabeza humana, algunas veces con fauces, cuerpo específico de objeto, extremidades humanas, elementos de vestimenta humana.

De esta forma se puede diferenciar en la presentación de los dioses seres combinados de humanos con rasgos de animal, animales con rasgos humanos, animal con rasgos de otro animal, planta con rasgos humanos y objeto con rasgos humanos.

El ser «seres combinados» caracteriza a las divinidades, y especialmente son las combinaciones entre humanos y animales las que sobresalen más. Con una naturalidad asombrosa se asocian en las imágenes de los dioses elementos provenientes de los humanos y de los animales. Ahí están los dioses antropomorfos con sus transformaciones, en las cuales adquieren características de animales; ahí están las divi- nidades con cabezas zoomorfas con cuerpo de humano y también con extremidades humanas y con vestimenta de humano; y también aparecen las divinidades híbridas, las que combinan su cuerpo propio con extremidades antropomorfas. Especialmente los seres divinos con cabeza de animal son los que reúnen más rasgos humaniformes, tanto en su aspecto como en su comportamiento, y de esta forma se integran al mundo diario, tal como se lo imaginan los moches. De esta manera quizás se expresen particularidades, capacidades, formas de actuación de estas divinidades «combinadas».

Cuadro sinóptico: Las divinidades de la cultura mochica

\section{Divinidades antropomorfas}

Divinidad a-A: La divinidad con el casco y la corona de rayos.

Divinidad a-B: La divinidad con el casquete de cuernos, camisa metálica y collar de rueda.

Divinidad a-C: La divinidad con la corona de bandas y el adorno en la espalda.

Divinidad a-D: La divinidad con el casquete de dos bandas y el haz de armas.

Divinidad a-D(1): La divinidad a-D en forma de cangrejo.

Divinidad a-D(2): La divinidad a-D en forma de pez.

Divinidad a -E: La divinidad con el casquete semicircular.

Divinidad a-E(1): La divinidad a-E en forma de cangrejo.

Divinidad a-E(2): La divinidad a-E en forma de lapa.

Divinidad a-E(3): La divinidad a- E en forma de mazorca.

Divinidad a-F: La divinidad con el tocado de felino y el cinturón de serpientes.

Divinidad a-F(1): La divinidad a-F en forma de cangrejo.

Divinidad a-F(2): La divinidad a-F en forma de camarón. 
Divinidad a-F(3): La divinidad a-F en forma de pez.

Divinidad a-F(4): La divinidad a-F en forma de caracol.

Divinidad a-F(5): La divinidad a-F en forma de ciempiés.

Divinidad a-F(6): La divinidad a-F en forma de insecto.

Divinidad a-F(7): La divinidad a-F en forma de jaguar.

Divinidad a-F(6): La divinidad a-F en forma de yuca.

Divinidad a-G: La divinidad con las colinas de serpientes.

Divinidad a-H: La divinidad con la cara frontal y el anexo en forma de X.

Divinidad a-J: La divinidad con la pareja de ulluchu en el tocado y la piel de animal colgada.

Divinidad a-K: La divinidad con el tocado en forma de hoz y la vestimenta de círculos claros.

Divinidad a-L: La divinidad con los adornos circulares por ambos lados del tocado en forma de hoz.

Divinidad a-M: La divinidad con las culebras en la cabeza.

Divinidad a-N: La divinidad con el pelo largo.

\section{Divinidades zoomorfas}

Divinidad z-A: La divinidad iguana.

Divinidad z-B: La divinidad búho.

Divinidad z-C: La divinidad ave rapaz.

Divinidad z-D: La divinidad zorro.

Divinidad z-E: La divinidad murciélago.

Divinidad z-F: La divinidad picaflor.

Divinidad z-G: La divinidad ciervo.

Divinidad z-H: La divinidad cangrejo.

Divinidad z-J: La divinidad culebra.

Divinidad z-K: La divinidad águila.

\section{Divinidades híbridas}

Divinidad h-A: La divinidad monstruo strombus.

Divinidad h-B: La divinidad monstruo pez.

Divinidad h-C: La divinidad con aletas y mechones.
Divinidad h-D: La divinidad en forma de animal rapaz con la cabeza dirigida hacia atrás y la cresta.

Divinidad h-E: La divinidad con el anexo de la cola llena de peces.

Divinidad h-F: La divinidad animal rapaz con el anexo lleno de adornos de escalera.

Divinidad h-G: La divinidad de las tres caras.

Divinidad h-H: La divinidad con la cara frontal y el gorro de mechones.

Divinidad h-J: La divinidad con la cara compuesta.

Divinidad h-K: La divinidad animal rapaz con caracol.

Divinidad h-L: La divinidad en forma de bola.

IV. Divinidades fitomorfas

Divinidad p-A: La divinidad frijol.

Divinidad p-B: La divinidad mazorca.

V. Divinidades en forma de objeto

Divinidad o-A: La divinidad macana.

\section{Divinidades antropomorfas}

Divinidad a-A: La divinidad con el casco y la corona de rayos.

Rasgos antropomorfos:

Cabeza/cuerpo/extremidades: Antropomorfos.

Tocado: Casco de guerrero con un adorno superior en forma de hacha, con protector de espalda.

Vestimenta: Muestra una camisa blindada, falda protectora, así como el protector coxal característico de los guerreros.

Adornos: Collar, nariguera y orejeras redondas.

Rasgos zoomorfos:

Cabeza: Fauces felínicas.

Atributos: Rayos que rodean la figura.

Requisitos: Frecuentemente lleva porra y escudo.

(Fig. 1-4)

Divinidad a-B: La divinidad con el casquete de cuernos, camisa metálica y collar de rueda.

Rasgos antropomorfos:

Cabeza/cuerpo/extremidades: Antropomorfos. 
Tocado: Mayormente muestra un casquete con una divisa en forma de media luna, de la cual salen dos apéndices; algunas veces muestra un casquete con adorno en forma de hacha, gran tocado de abanico de plumas, del cual salen dos bandas dentadas largas.

Vestimenta: Camisa blindada de cuadrados metálicos con borde dentado, del cual cae una banda metálica de iguales características a manera de protector coxal. Frecuentemente muestra un cuello grande en forma de rueda. Camisa y faldellín algunas veces sin aplicaciones metálicas.

Adornos: Nariguera y orejeras en forma de roseta.

\section{Rasgos zoomorfos:}

Cabeza: Fauces felinícas.

\section{(Fig. 5-8)}

Divinidad a-C: La divinidad con la corona de bandas y el adorno en la espalda.

\section{Rasgos antropomorfos:}

Cabeza/cuerpo/extremidades: Antropomorfos.

Tocado: Un aro con adornos redondos, con una serie de bandas adornadas hacia arriba. Aros algunas veces anchos, otras delgadas. Igualmente hay variación de las bandas, con borde liso o dentado. Las bandas algunas veces terminan en cabezas de culebras. Las bandas están paradas o ligeramente inclinadas. El protector de espalda también muestra variaciones, algunas veces cae como una chalina, otras veces como trenzas, o se encuentra compuesto por una serie de partes escalonadas, y frecuentemente termina en cabezas de culebra. Algunas veces el protector de espalda lleva añadidos adornos en forma de alas de insectos.

Vestimenta: Camisón largo hasta las rodillas, algunas veces con cinturón, con adornos circulares o de rayas, formas zigzagueantes y de redes.

Adornos: Orejera en forma de roseta.

\section{Rasgos zoomorfos:}

Cabeza: Fauces poco pronunciadas en forma de rombo.

Atributos: Algunas veces rodeado por rayos.

Requisitos: Frecuentemente lleva una copa.

(Fig. 9-12)

Divinidad a-D: La divinidad con el casquete de dos bandas y el haz de armas.

\section{Rasgos antropomorfos:}

Cabeza/cuerpo/extremidades: Antropomorfos. Tocado: Aro con dos bandas pronunciadas hacia arriba, amarrado con tela debajo del mentón. Frecuentemente fijado con un broche. Las bandas levantadas del tocado frecuentemente terminan en cabezas de culebra. Sobre el aro o la banda del tocado siempre se muestra parte del pelo, algunas veces en forma de volutas, otras veces en forma lisa.

Vestimenta: Camisa, frecuentemente hecha de red, tela simple que cubre la cadera también frecuentemente sin camisa. Cinturón ancho, del cual salen generalmente dos bandas que terminan en cabeza de culebra.

Adornos: Orejera en forma de roseta o de culebra.

\section{Rasgos zoomorfos:}

Cabeza: Fauces de forma romboidal.

Atributos: Rodean al personaje atados de armas, compuesto de porra y escudo, frecuentemente se añade estólica, lanzas y honda.

Requisitos: Generalmente porta remo, anzuelo, un hacha o un pez largo

(Fig. 13-16)

Divinidad a-D(1): La divinidad a-D en forma de cangrejo.

\section{Rasgos antropomorfos:}

Cabeza: Cabeza antropomorfa con el casquete de dos bandas o rayos.

Extremidades: Piernas humanas al lado de las de cangrejo

Tocado:

Vestimenta:

Adornos: 


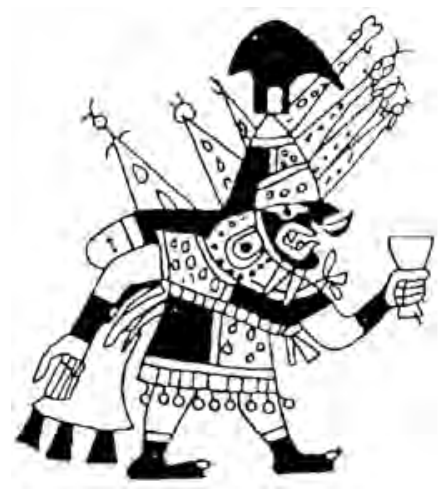

Fig. 1

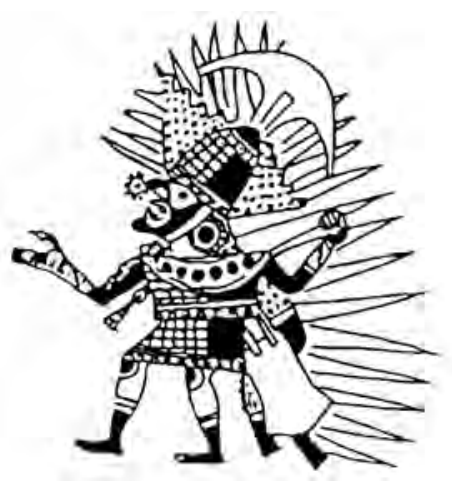

Fig. 4

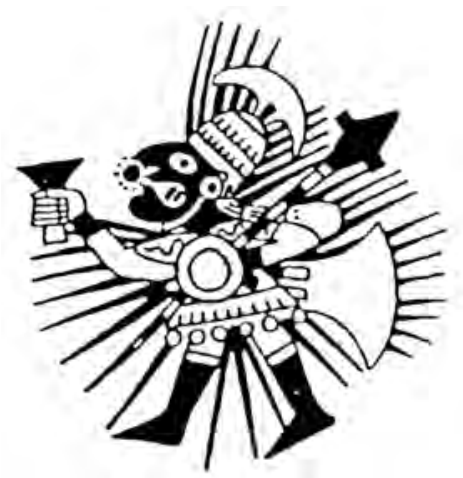

Fig. 2

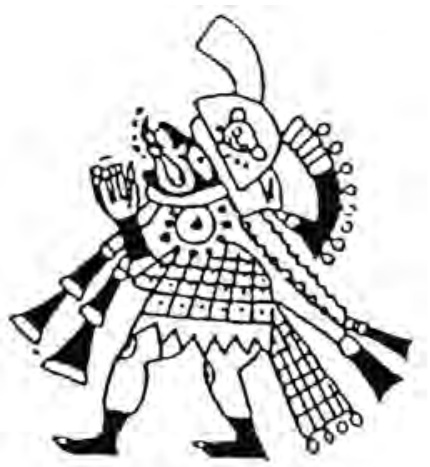

Fig. 5

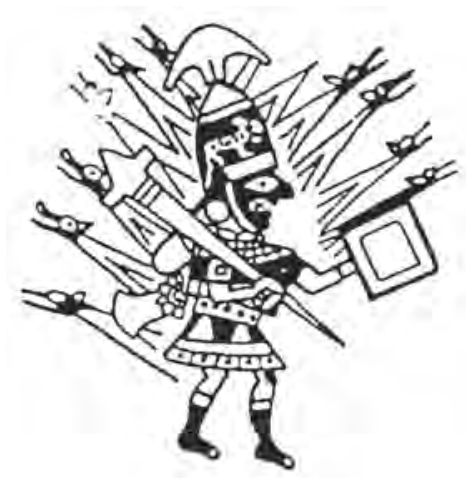

Fig. 3

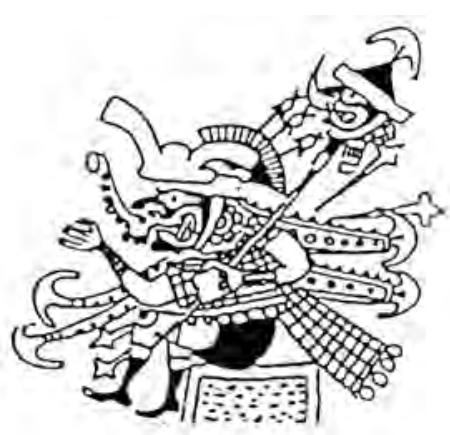

Fig. 6

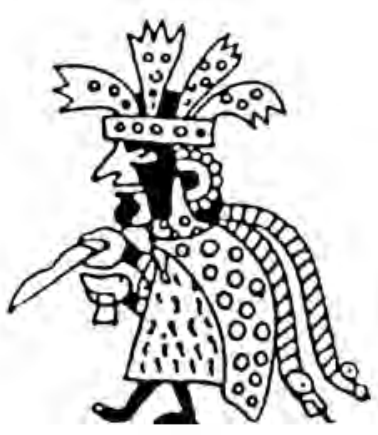

Fig. 9 


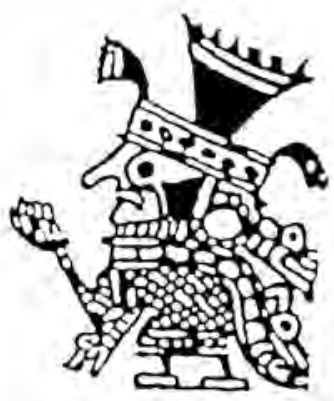

Fig. 10

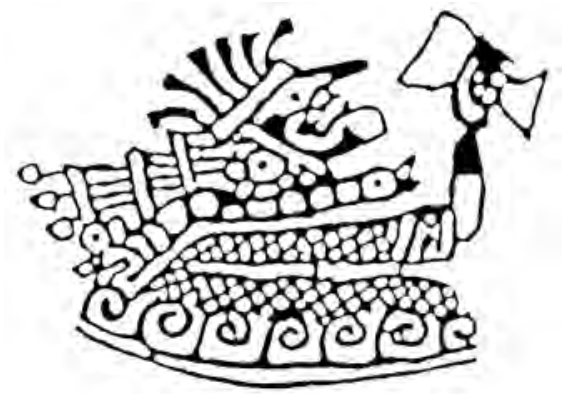

Fig. 11

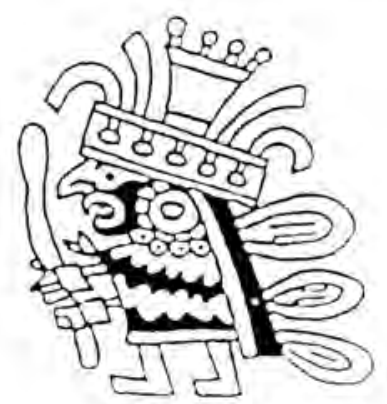

Fig. 12

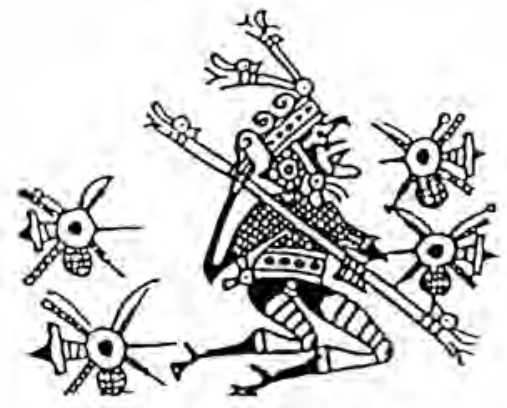

Fig. 13

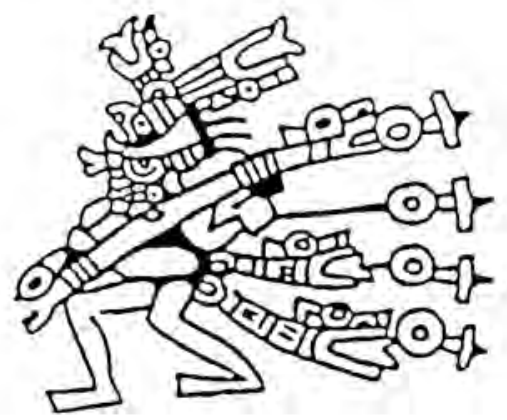

Fig. 14

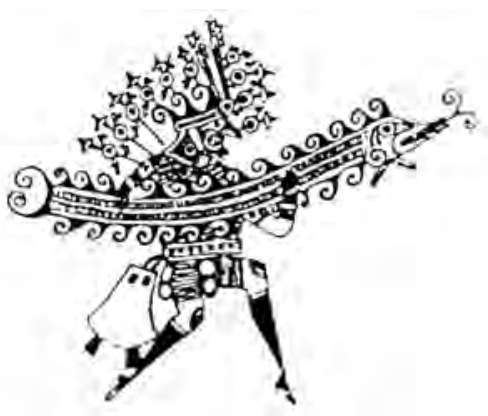

Fig. 15

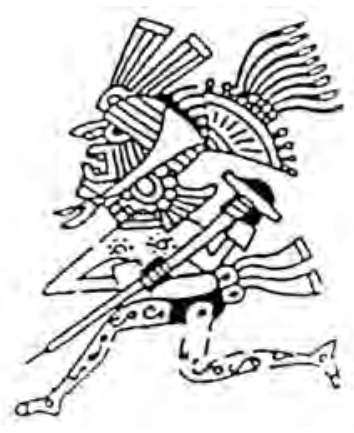

Fig. 16

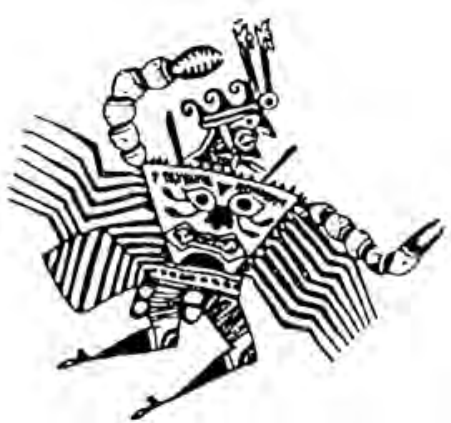

Fig. 17 
Rasgos zoomorfos:

Cabeza: Fauces felínicas.

Cuerpo: Caparazón de cangrejo con fauces felínicas, abajo siempre se muestra la sección inferior del cuerpo como anexo.

Extremidades: Generalmente se muestra cuatro pares de piernas de cangrejo, pinzas de cangrejo.

(Fig. 17-20)

Divinidad a-D(2): La divinidad a-D en forma de pez.

\section{Rasgos antropomorfos:}

Cabeza: Cabeza antropomorfa con el casquete de dos bandas o rayos.

Extremidades: Brazos humanos, algunas veces piernas.

Tocado:

Vestimenta:

Adornos:

Rasgos zoomorfos:

Cabeza: Fauces felínicas

Cuerpo: Cuerpo de pescado alargado con aletas y cola, dibujo de escamas.

Requisitos: Cuchillo

(Fig. 21-24)

Divinidad a -E: La divinidad con el casquete semicircular.

\section{Rasgos antropomorfos:}

Cabeza/cuerpo/extremidades: Antropomorfos.

Tocado: plancha semicircular grande, con dibujo de rayos, frecuentemente perlas al borde, con cabeza de felino al centro

Vestimenta: camisón hasta la rodilla o camisa con taparrabo, frecuentemente cuello ancho y redondo.

Adornos: orejeras en forma de cabeza de culebra y collar de perlas grandes.

Rasgos zoomorfos:

Cabeza: Fauces felínicas.

(Fig. 25-28)
Divinidad a-E(1): La divinidad a-E en forma de cangrejo.

Rasgos antropomorfos:

Cabeza: Antropomorfa.

Extremidades: brazos humanos y piernas.

Tocado: casquete con plancha semicircular característica, con felino al centro.

Adomos: orejeras de cabezas de culebras y collar de perlas.

Rasgos zoomorfos:

Cabeza: Fauces felínicas.

Cuerpo: caparazón de cangrejo, abajo siempre se muestra la sección inferior del cuerpo como anexo.

Extremidades: pinzas de cangrejo pueden sustituir los brazos humanos, frecuentemente se añade extremidades de cangrejo al caparazón.

(Fig. 29-32)

Divinidad a-E(2): La divinidad a-E en forma de lapa.

Rasgos antropomorfos:

Cabeza: Antropomorfa.

Extremidades: brazos y piernas humanas.

Tocado: casquete con plancha semicircular con cabeza de felino al centro.

Vestimenta: camisa con cuello dentado.

Adomos: orejera en forma de cabeza de culebra.

Rasgos zoomorfos:

Cabeza: Fauces felínicas

Cuerpo: caparazón de lapa con círculos concéntricos.

(Fig. 33a-33b)

Divinidad a-E(3): La divinidad a- E en forma de mazorca.

Rasgos antropomorfos:

Cabeza: Antropomorfa.

Tocado: Plancha semicircular con felino al centro.

Adornos: Orejeras en forma de cabeza de culebra. 


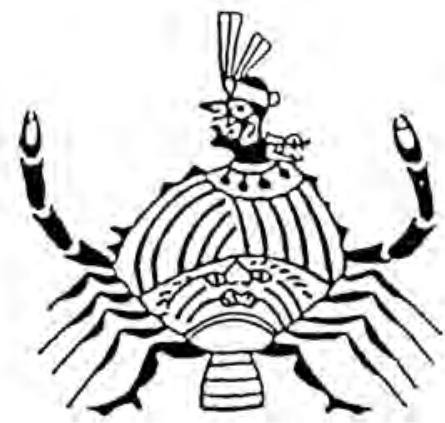

Fig. 18

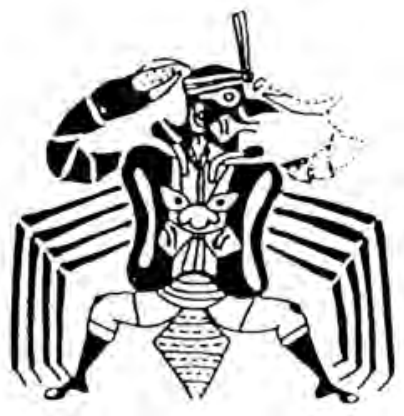

Fig. 19

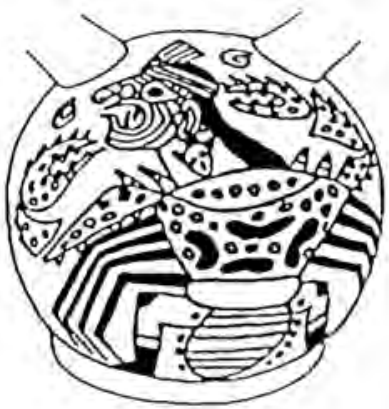

Fig. 20

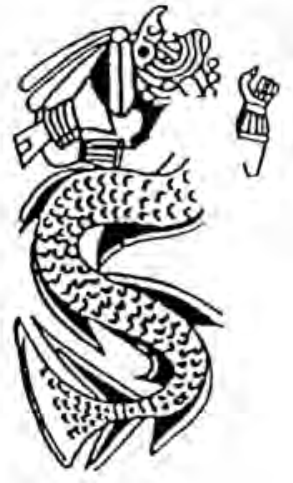

Fig. 21

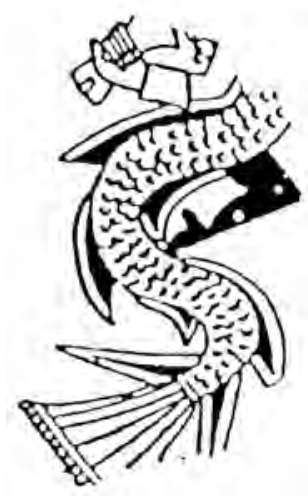

Fig. 22

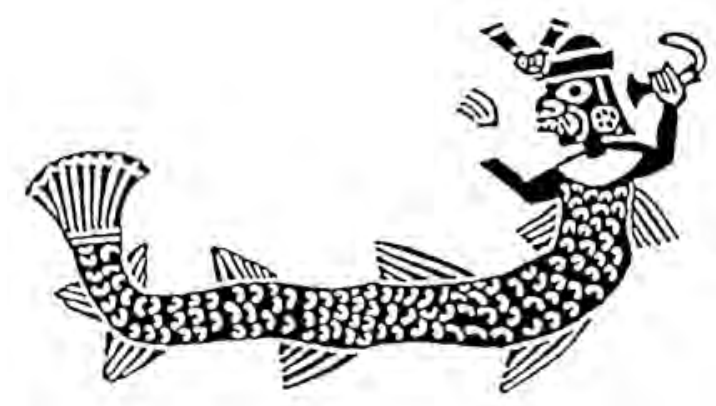

Fig. 23

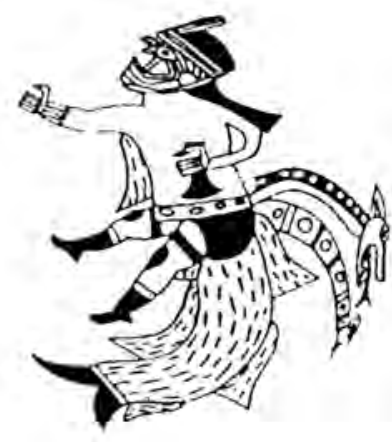

Fig. 24

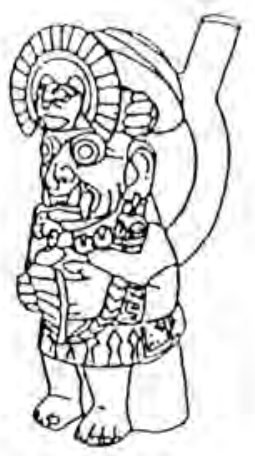

Fig. 25

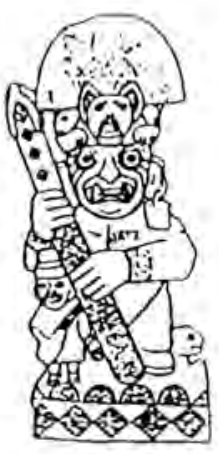

Fig. 26 


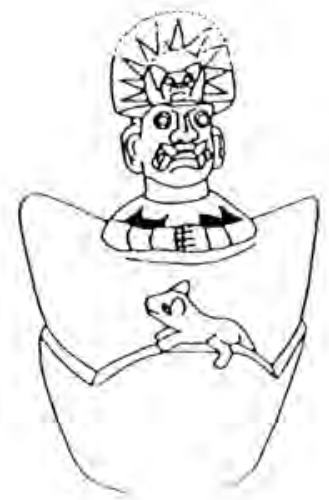

Fig. 27

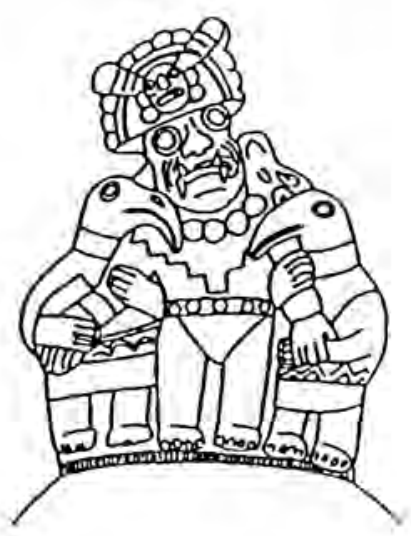

Fig. 28

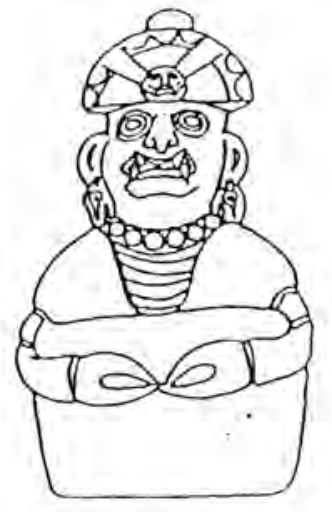

Fig. 29

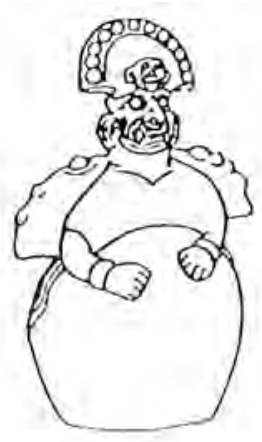

Fig. 30

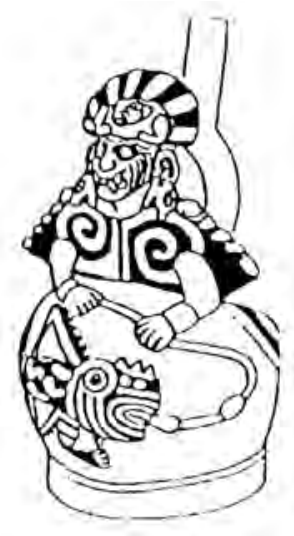

Fig. 31

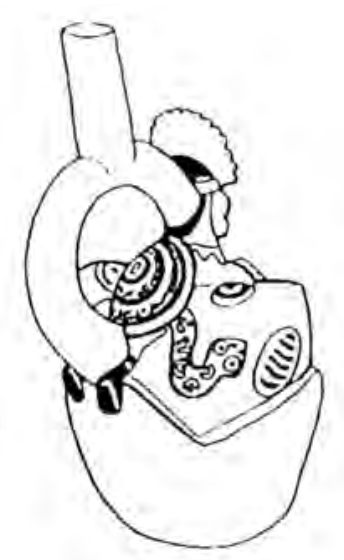

Fig. 33b

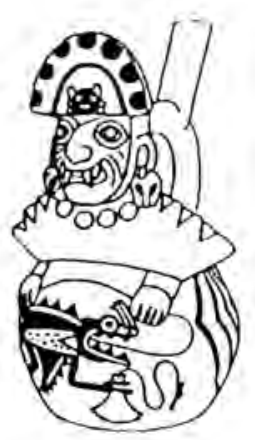

Fig. 32

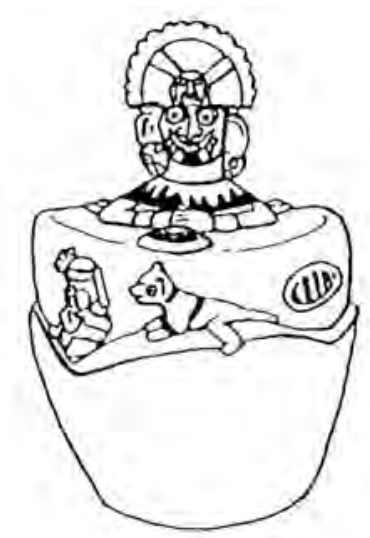

Fig. 33a

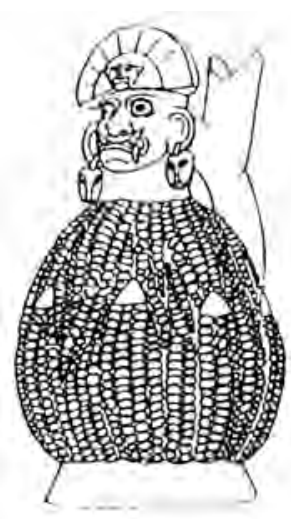

Fig. 34 
Rasgos zoomorfos:

Cabeza: Fauces felínicas.

Rasgos fitomorfos: El cuerpo está formado por mazorcas.

(Fig. 34)

Divinidad a-F: La divinidad con el tocado de felino y el cinturón de serpientes.

Rasgos antropomorfos:

Cabeza/cuerpo/extremidades: Antropomorfos.

Tocado: aro formado por piel de felino, con cabeza para adelante, extremidades laterales y cola hacia atrás; abanico de plumas

Vestimenta: Camisa frecuentemente con dibujo escalonado en forma de $\mathrm{V}$, algunas veces con camisa, de cuadrados metálicos y taparrabo.

\section{Rasgos zoomorfos:}

Cabeza: Fauces felínicas.

Atributos: Cinturón de serpientes, normalmente de dos, algunas veces con una o tres, dibujo del cinturón segmentado, anillado, dentado o con manchas.

Requisitos: Hacha o cuchillo, algunas veces porra, estólica, o también sonaja.

(Fig. 35-38)

Divinidad a-F(1): La divinidad a-F en forma de cangrejo.

Rasgos antropomorfos:

Cabeza/tocado: Humana con tocado característico.

Extremidades: siempre con piernas antropomorfas, raras veces con brazos.

\section{Rasgos zoomorfos:}

Cabeza: Fauces felínicas.

Cuerpo: caparazón de cangrejo visto de frente, con cara humana con fauces felínicas, abajo siempre se muestra la sección inferior del cuerpo como anexo.

Extremidades: cuatro parejas de extremidades de cangrejo.

(Fig. 39-42)

Divinidad a-F(2): La divinidad a-F en forma de camarón.

Rasgos antropomorfos:

Cabeza/tocado: Humana con tocado característico.

Cuerpo/extremidades: Frecuentemente conserva cuerpo antropomorfo, por lo menos con una, pero también con dos piernas humanas.

Vestimenta: Cuerpo humano con taparrabo y camisa.

Rasgos zoomorfos:

Cabeza: Antenas largas nacen de fauces felínicas.

Cuerpo: Cuerpo de langosta anexado al cuerpo humano con cola de abanico.

Extremidades: Múltiples de langosta y pinzas grandes.

Atributos: Algunas veces se añade el cinturón de serpientes.

(Fig. 43-46)

Divinidad a-F(3): La divinidad a-F en forma de pez.

Rasgos antropomorfos:

Cabeza/tocado: Humana con tocado característico Cuerpo/vestimenta: algunas veces parte de cuerpo humano y vestimenta al lado de cuerpo de pez.

Extremidades: siempre muestra extremidades humanas.

Rasgos zoomorfos:

Cabeza: Fauces felínicas.

Cuerpo: Pez con aletas y cola.

Requisitos: Hacha y cabeza trofeo.

(Fig. 47-48)

Divinidad a-F(4): La divinidad a-F en forma de caracol.

Rasgos antropomorfos:

Cabeza/cuerpo/extremidades: Antropomorfos.

Tocado: Característico de F.

Vestimenta: Camisa, taparrabo o faldellín.

Rasgos zoomorfos:

Cabeza: Fauces felínicas. 


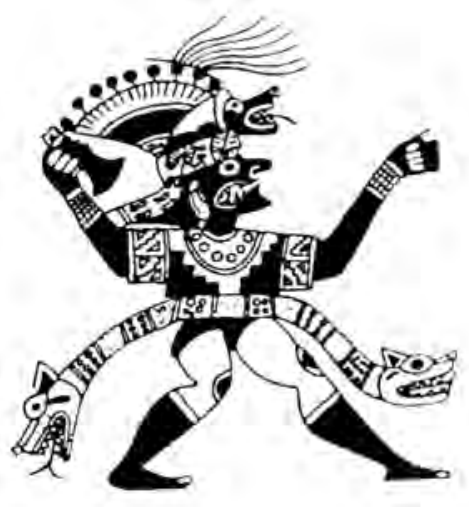

Fig. 35

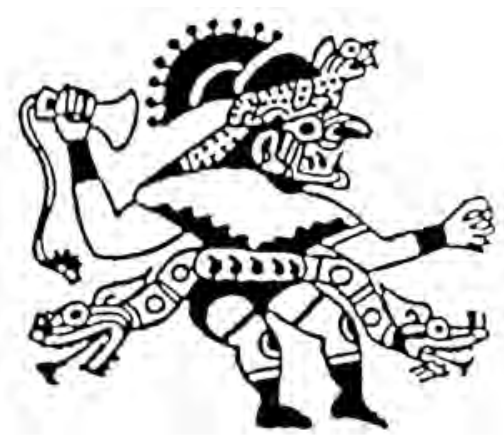

Fig. 38

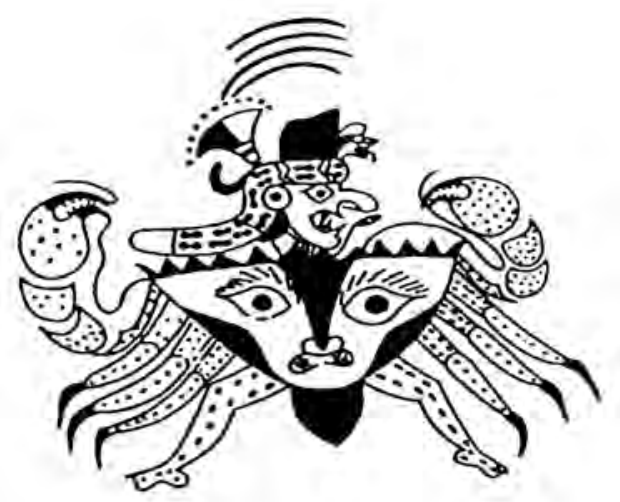

Fig. 40

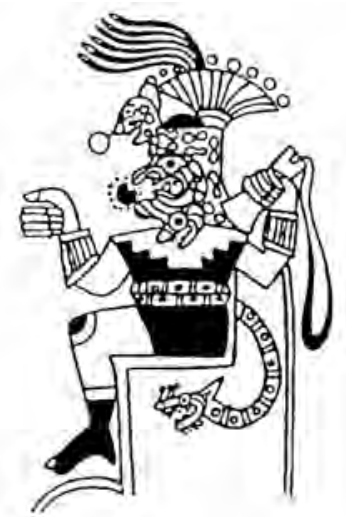

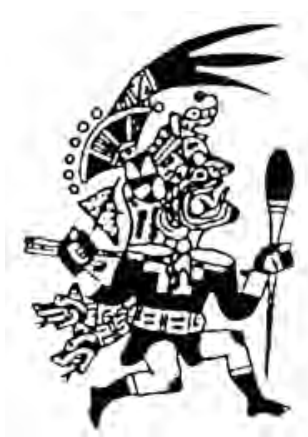

Fig. 37

Fig. 36

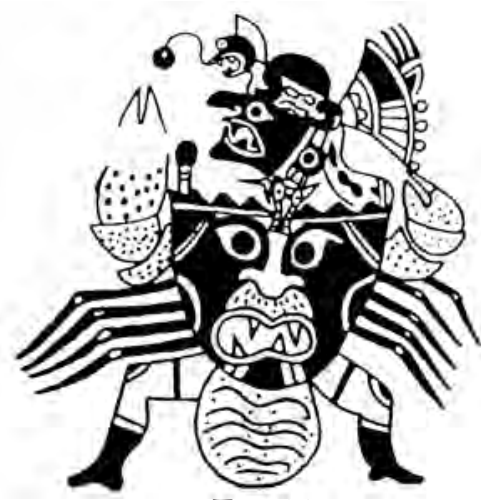

Fig. 39

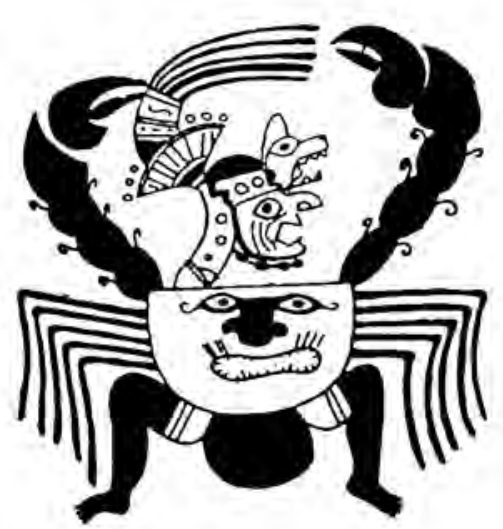

Fig. 41 
Atributos: Caparazón de caracol añadido como anexo, cinturón de serpientes.

(Fig. 49-50)

Divinidad $a-F(5)$ : La divinidad a-F en forma de ciempiés.

Rasgos antropomorfos:

Cabeza/cuerpo/extremidades: Antropomorfos. Tocado: De felino característico de F.

Vestimenta: Camisa y faldellín.

\section{Rasgos zoomorfos:}

Cabeza: Fauces felínicas, frecuentemente con antenas.

Atributos: Cuerpo de ciempiés, segmentado con cabeza trasera y pinza.

(Fig. 51-52)

Divinidad a-F(6): La divinidad a-F en forma de insecto.

Rasgos antropomorfos:

Cabeza/cuerpo/extremidades: Antropomorfos.

Tocado: De felino característico.

Vestimenta: camisa, taparrabo o faldellín.

Adornos:

Rasgos zoomorfos:

Cabeza: Fauces felínicas, frecuentemente antenas.

Atributos: Se añade dos o tres alas de insecto al cuerpo, parte trasera de cuerpo de insecto (libélula) como anexo.

(Fig. 53-56)

Divinidad a-F(7): La divinidad a-F en forma de jaguar.

Rasgos antropomorfos:

Cabeza/tocado: humana con tocado característico.

Rasgos zoomorfos:

Cabeza: fauces felínicas.

Cuerpo/extremidades: Cuerpo, extremidades y cola de jaguar.

(Fig. 57)

Divinidad a-F(8): La divinidad a-F en forma de yuca.

Rasgos antropomorfos:

Cabeza/tocado: Humana con tocado característico.

Extremidades: brazos humanos.

Rasgos fitomorfos:

Cabeza: Dos ramas en tocado.

Cuerpo: Yuca

Rasgos zoomorfos: Cabeza: fauces felínicas.

(Fig. 58)

Divinidad a-G: La divinidad con las colinas de serpientes.

\section{Rasgos antropomorfos:}

Cabeza/cuerpo/extremidades: antropomorfos. Tocado: Tres o cuatro formas redondas que se apoyan sobre la cabeza, algunas veces un anillo con cabeza de animal, otras veces una plancha semicircular, también sin tocado alguno.

Vestimenta: Camisón hasta la rodilla, cuello ancho en forma de rueda.

Adornos: Oorejeras variadas, algunas veces en forma de cabeza de culebra, o de dos planchas rectangulares.

Rasgos zoomorfos: Cabeza: fauces felínicas.

Atributos: La divinidad siempre aparece de frente entre dos o mas colinas, que parecen ser parte del cuerpo, frecuentemente es acompañada por dos serpientes laterales que se enroscan alrededor de las colinas con las cabezas encima del tocado de la divinidad.

(Fig. 59-62)

Divinidad a-H: La divinidad con la cara frontal y el anexo en forma de X.

Rasgos antropomorfos:

Cabeza/cuerpo/extremidades: Antropomorfos, excepcional es la presentación en face y los pies dirigidos hacia afuera.

Tocado: Casquete formado por pelos o bandas semicirculares, algunas veces volutas en la misma forma, también aro del cual salen mechones 


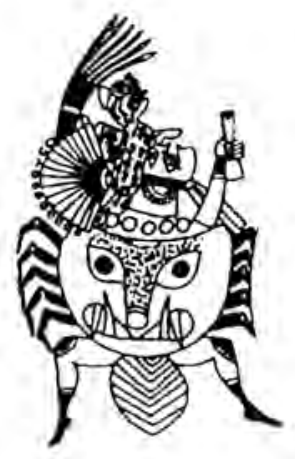

Fig. 42

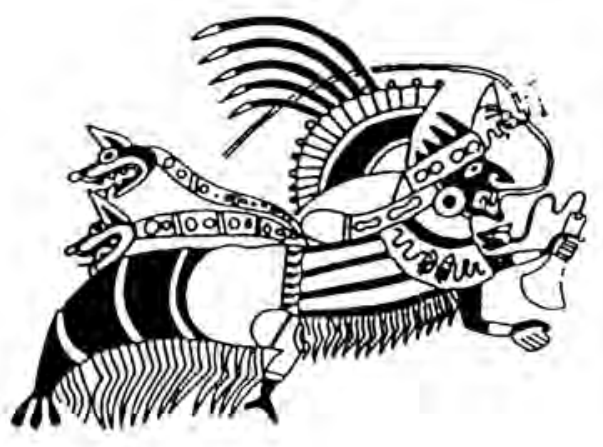

Fig. 43

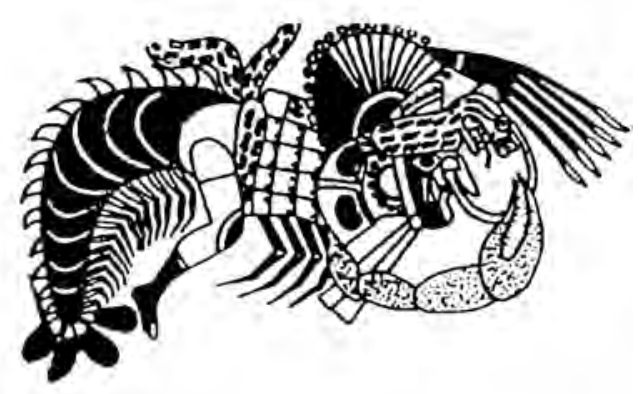

Fig. 44

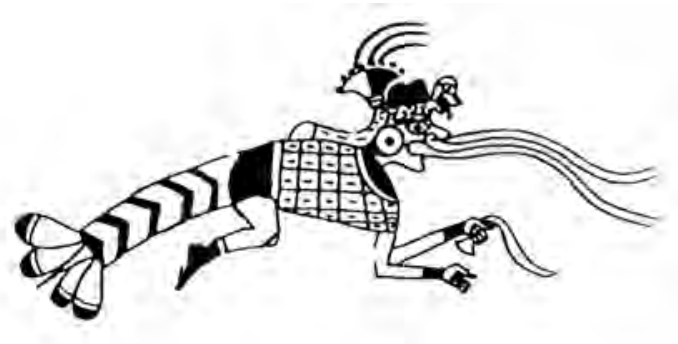

Fig. 45

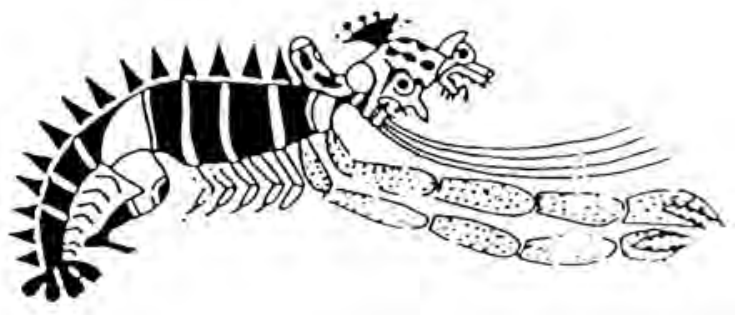

Fig. 46
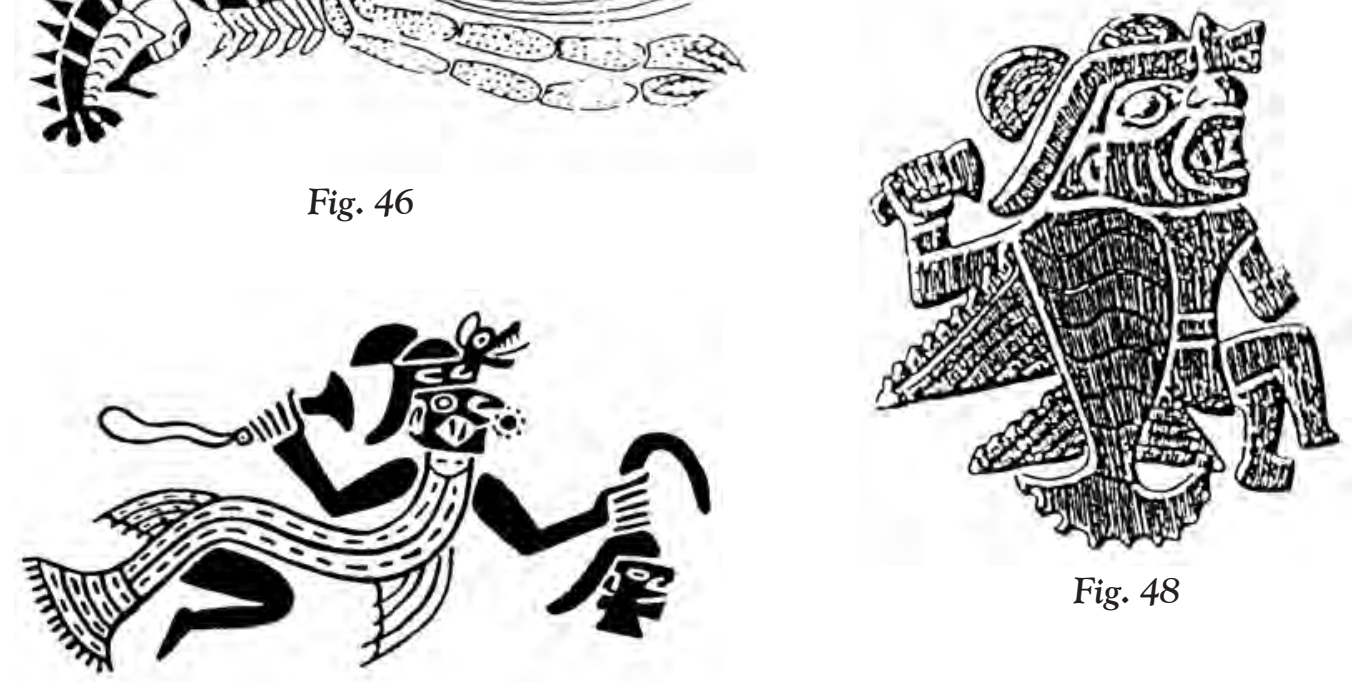

Fig. 48

Fig. 47 


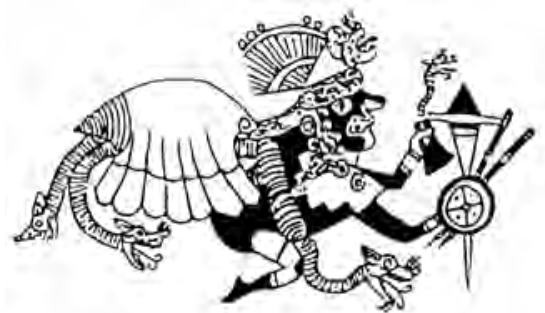

Fig. 49

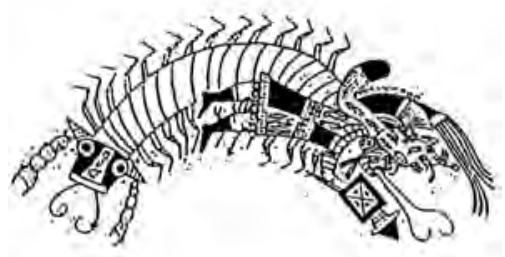

Fig. 52

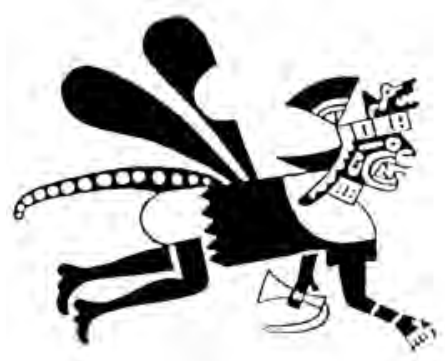

Fig. 55

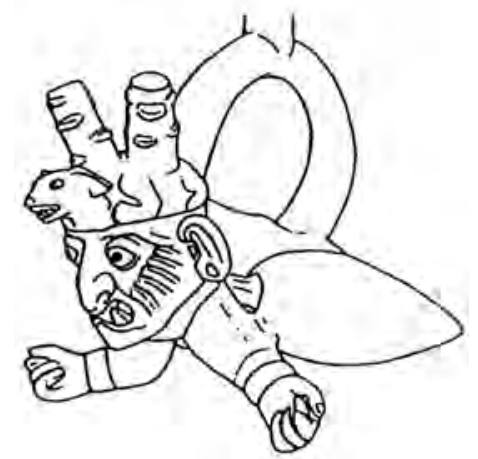

Fig. 58

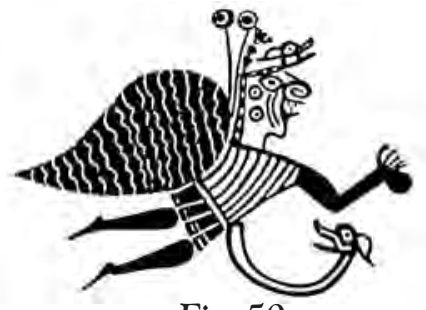

Fig. 50

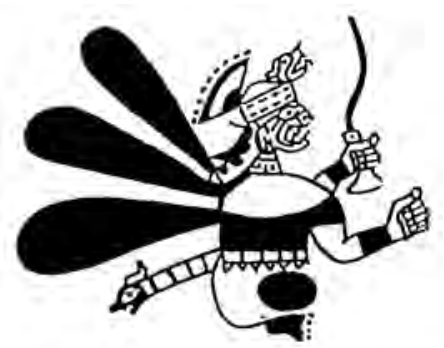

Fig. 53

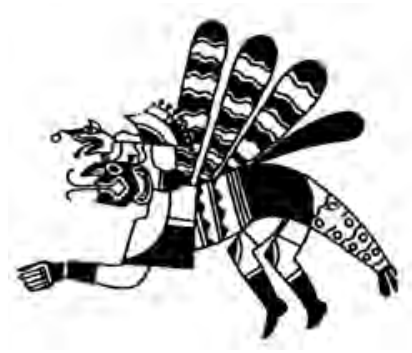

Fig. 56

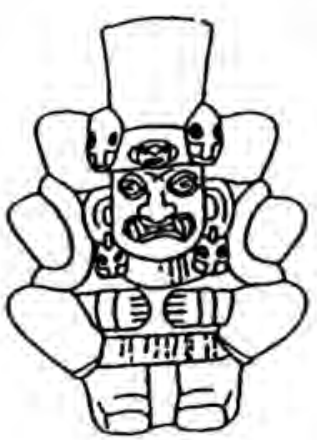

Fig. 59

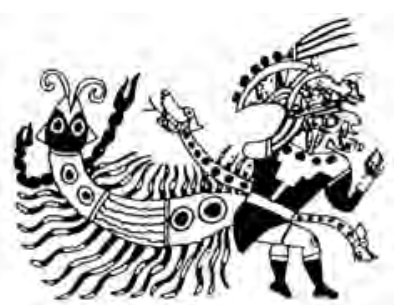

Fig. 51

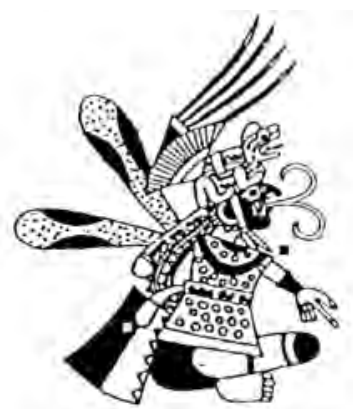

Fig. 54

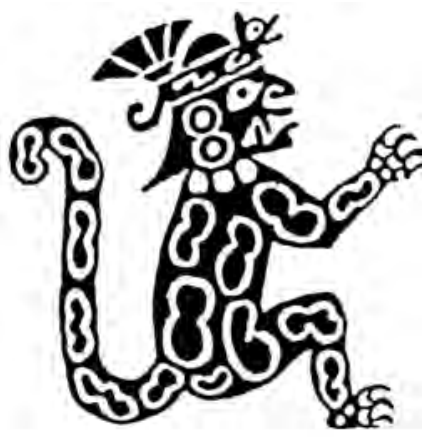

Fig. 57

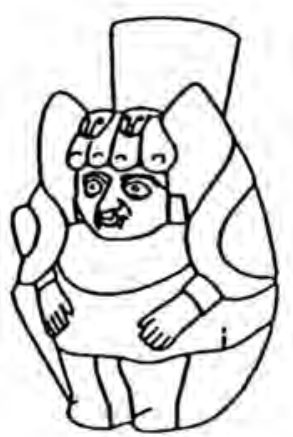

Fig. 60 
Vestimenta: Camisa de rayas verticales y taparrabo.

Adornos: Orejera de dos redondelas superpuestas.

Rasgos zoomorfos:

Cabeza: Fauces felinicas.

Atributos: Cuatro anexos en forma de alas agregadas a la espalda, segmentadas, con aspecto de molino de viento.

Requisitos: Hacha y cabeza trofeo.

(Fig. 63-66)

Divinidad a-J: La divinidad con la pareja de ulluchu en el tocado y la piel de animal colgada.

Rasgos antropomorfos:

Cabeza/cuerpo/extremidades: Antropomorfos.

Tocado: aro con dos frutos de ulluchu.

Vestimenta: camisa a cuadros y con borde dentado (probablemente de metal), taparrabo.

Adornos: Orejera de placa redonda colgada.

Rasgos zoomorfos:

Cabeza: Fauces felínicas.

Atributos: Piel de animal colgada.

Requisitos: Bolsa en el brazo.

(Fig. 67-70)

Divinidad a-K: La divinidad con el tocado en forma de hoz y la vestimenta de círculos claros. Rasgos antropomorfos:

Cabeza/cuerpo/extremidades: Antropomorfos. Tocado: Aro alrededor de la cabeza con elemento parado en forma de cuchillo, protector de espalda añadido, compuesto de una serie de elementos escalonados.

Vestimenta: Vestimenta y gran cuello circular adornado con círculos claros

Rasgos zoomorfos:

Cabeza: Fauces felínicas.

Requisitos: Carga caracol Strombus.

(Fig. 71-74)

Divinidad a-L: La divinidad con los adornos circulares por ambos lados del tocado en forma de hoz.
Rasgos antropomorfos:

Cabeza/cuerpo/extremidades: Antropomorfos. Tocado: Tocado en forma de cuchillo parado, al cual se agrega por ambos lados una redondela.

Vestimenta: Camisón largo hasta las rodillas.

Adornos: Orejeras circulares.

Rasgos zoomorfos:

Cabeza: Fauces felínicas.

Atributos: Serpiente bicéfala, algunas veces con rayos rodea la figura.

Requisitos: Frecuentemente carga porra, escudo o lanzas en las manos.

(Fig. 75-78)

Divinidad a-M: La divinidad con las culebras en la cabeza.

Rasgos antropomorfos:

Cabeza/cuerpo/extremidades: Antropomorfo. Tocado: Sin tocado y calvo.

Vestimenta: Camisón largo o taparrabo.

Adornos: Par de orejeras superpuestas.

Rasgos zoomorfos:

Cabeza:Fauces felínicas.

Atributos: Dos, tres o cuatro culebras colocadas sobre la cabeza.

(Fig. 79-82)

Divinidad a-N: La divinidad con el pelo largo.

Rasgos antropomorfos:

Cabeza/cuerpo/extremidades: Antropomorfos.

Peinado: Pelo suelto largo sin tocado.

Vestimenta: camisa y taparrabo.

Rasgos zoomorfos:Cabeza: fauces felínicas.

(Fig. 83-86)

\section{Divinidades zoomorfas}

Divinidad z-A: La divinidad iguana.

Rasgos zoomorfos:

Cabeza: Pronunciada de iguana, algunas veces con dentadura felínica.

Cuerpo: Cola de iguana que nace de las caderas hacia atrás. 


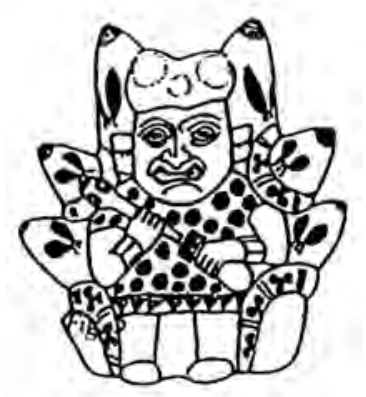

Fig. 61

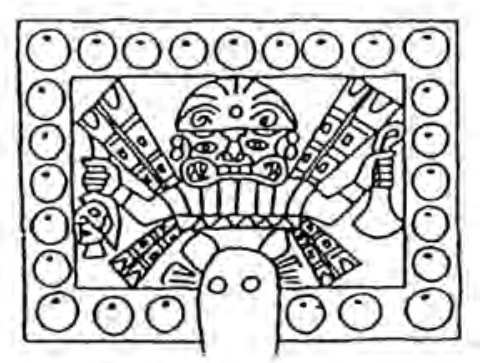

Fig. 64

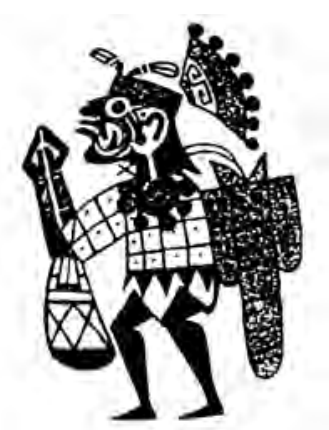

Fig. 67

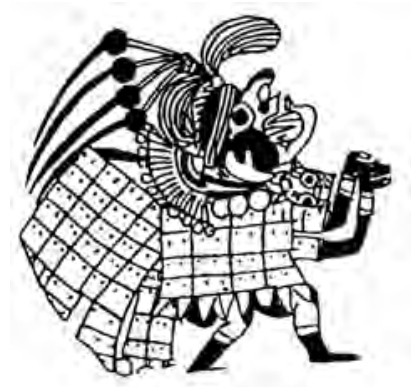

Fig. 70

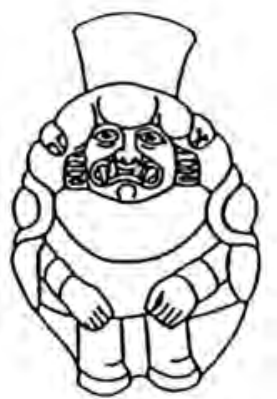

Fig. 62

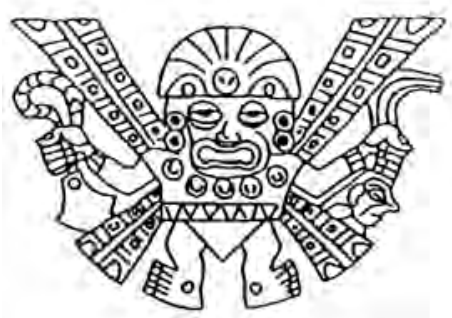

Fig. 65

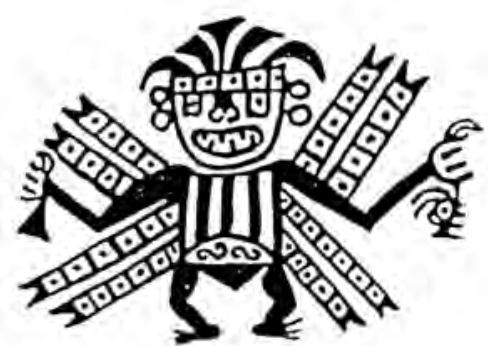

Fig. 63

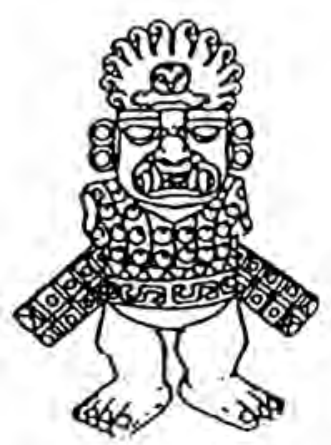

Fig. 66

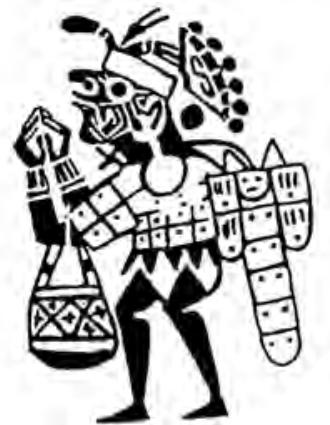

Fig. 68

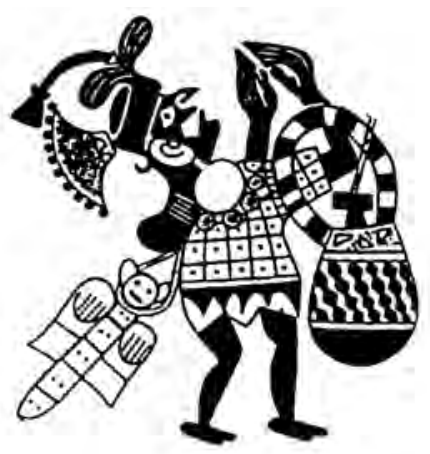

Fig. 69

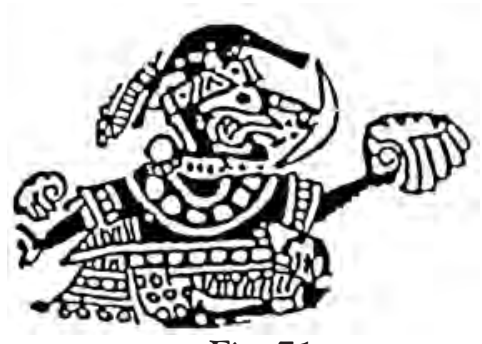

Fig. 71

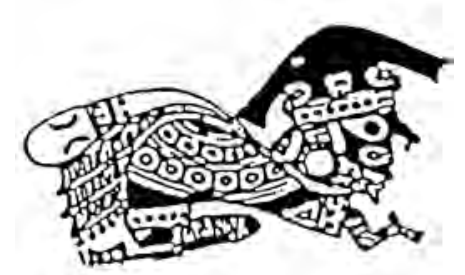

Fig. 72 


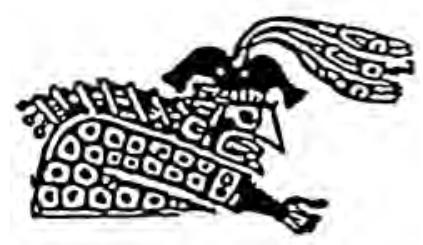

Fig. 73

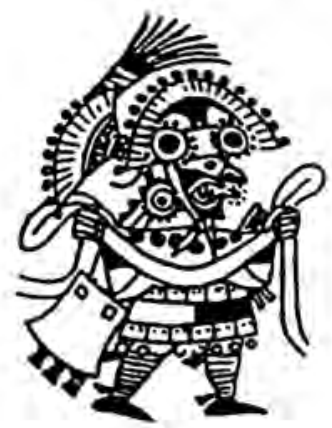

Fig. 76

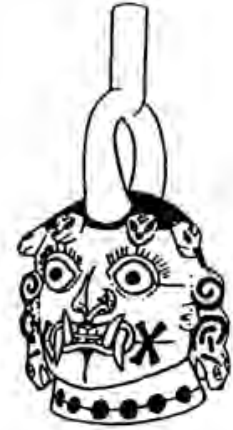

Fig. 79

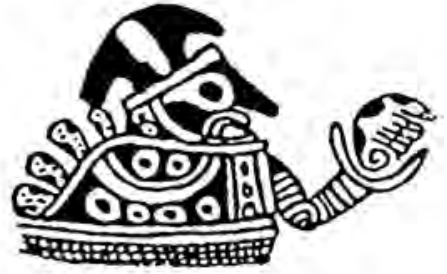

Fig. 74

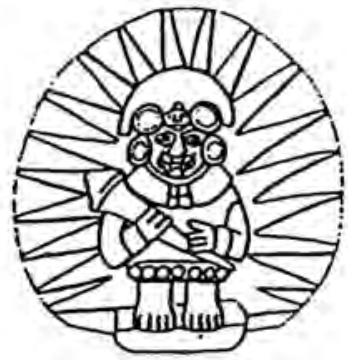

Fig. 77

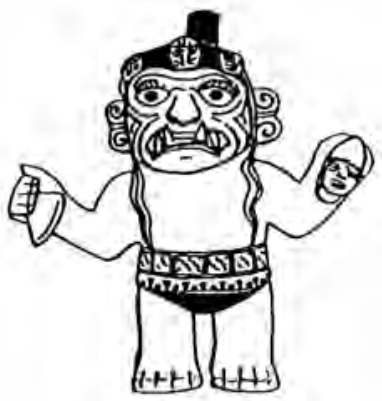

Fig. 80

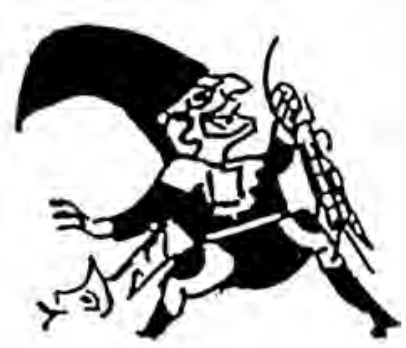

Fig. 83

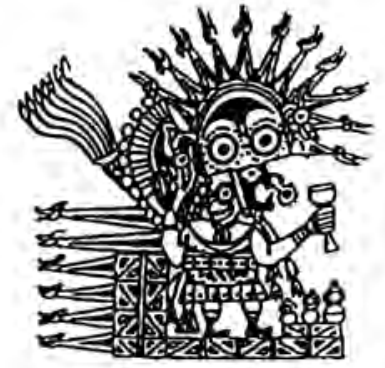

Fig. 75
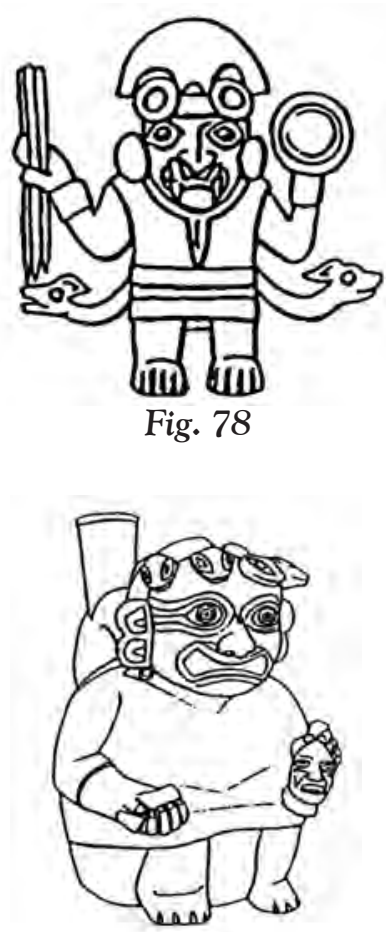

Fig. 81

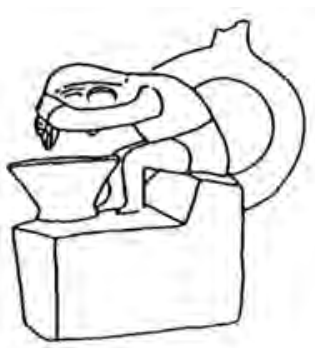

Fig. 84

Fig. 82 
Rasgos antropomorfos:

Cuerpo/extremidades: Antropomorfos.

Tocado: En forma de ave, con abanico de plumas.

Vestimenta: Camisa y taparrabo, cinturón atado.

(Fig. 87-90)

Divinidad z-B: La divinidad búho.

\section{Rasgos zoomorfos:}

Cabeza: Caracterizada por los ojos de búho rodeados por plumas y un borde de plumas en el mentón. En las comisuras del pico de ave rapaz se coloca una dentadura felínica. Cuerpo: Alas y cola de ave añadidos al cuerpo humaniforme.

Extremidades: Algunas veces se pone garras a las extremidades antropomorfas.

\section{Rasgos antropomorfos:}

Cuerpo/extremidades: Por lo general antropomorfos.

Tocado: Variado, casco con emblema sobrepuesto en forma de hacha, casquete con símbolo escalonado por ambos lados y hacha sobrepuesta, también hay gorros simples amarrados con tela.

Vestimenta: camisa y faldellín, algunas veces un manto con dibujo rediforme, quizás hecho de placas de metal, raras veces camisón.

Requisitos: Frecuentemente porra, acompañada de escudos, estólica y lanzas.

(Fig. 91-94)

Divinidad z-C: La divinidad ave rapaz.

\section{Rasgos zoomorfos:}

Cabeza: cabeza achatada con pico aguileño, algunas veces con dientes felínicos.

Cuerpo: alas y cola de ave añadidos al cuerpo humaniforme.

Extremidades: frecuentemente garras sustituyen a los pies humaniformes.

\section{Rasgos antropomorfos:}

Cuerpo/extremidades: por lo general antro- pomorfos.

Tocado: casco de guerrero con emblema en forma de hacha sobrepuesta.

Vestimenta: camisa, taparrabo o faldellín.

Requisitos: Frecuentemente porra con escudo, estólica y lanzas.

(Fig. 95-98)

Divinidad z-D: La divinidad zorro.

Rasgos zoomorfos:

Cabeza: Alargada y puntiaguda, boca entreabierta con lengua que sale, hilera de dientes filudos.

Cuerpo: Al cuerpo humaniforme se añade una cola larga, la parte superior oscura, la inferior clara.

Rasgos antropomorfos:

Cuerpo/extremidades: Antropomorfos.

Tocado: Casco de guerrero con hacha sobrepuesta.

Vestimenta: Camisa y faldellín, con protector coxal.

Requisitos: Por lo general carga atado de armas con porra, escudo, estólica y lanzas.

(Fig. 99-102)

Divinidad z-E: La divinidad murciélago.

Rasgos zoomorfos:

Cabeza: Cabeza de murciélago con fauces abiertos con dientes filudos, orejas grandes con su lóbulo superior enrollado.

Cuerpo: Al cuerpo humaniforme se añade alas de murciélago simplificadas.

Rasgos antropomorfos:

Cuerpo/extremidades: Antropomorfos.

Tocado: Variado, casquete con hacha sobrepuesta y elementos escalonados por ambos lados, algunas veces turbante o divisa semicircular, frecuentemente sin tocado.

Vestimenta:Camisa, taparrabo o camisón.

Requisitos: Porra y humano sacrificado.

(Fig. 103-106) 


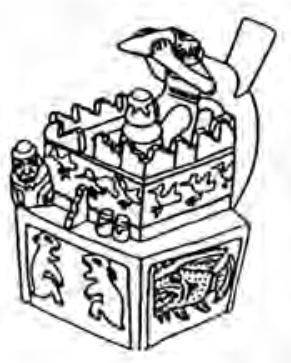

Fig. 85

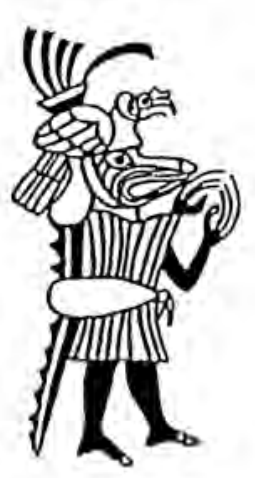

Fig. 88

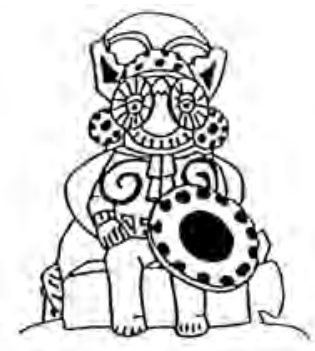

Fig. 91

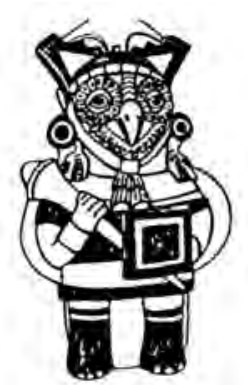

Fig. 94

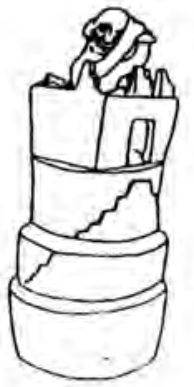

Fig. 86

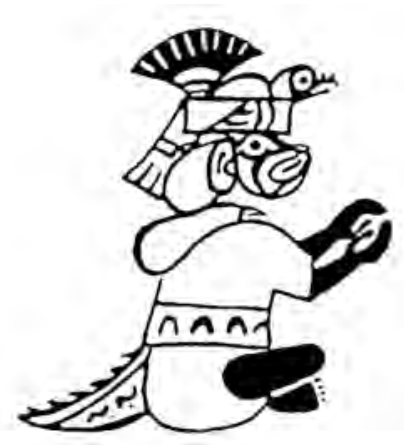

Fig. 89

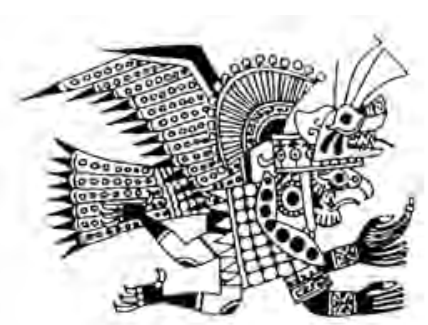

Fig. 92

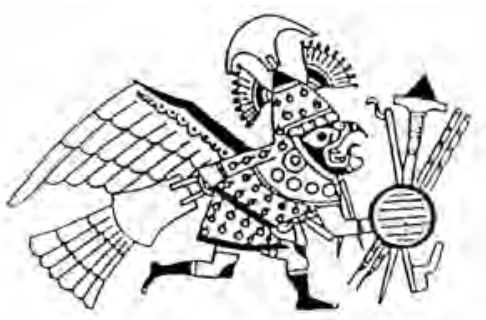

Fig. 95

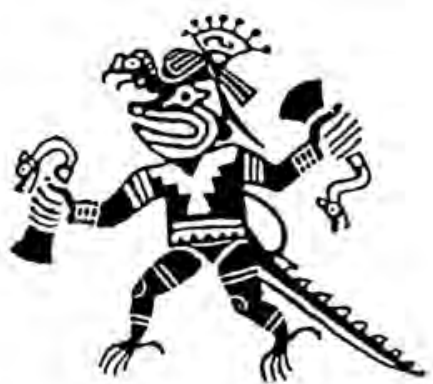

Fig. 87

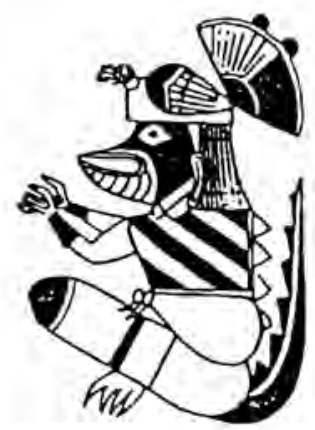

Fig. 90

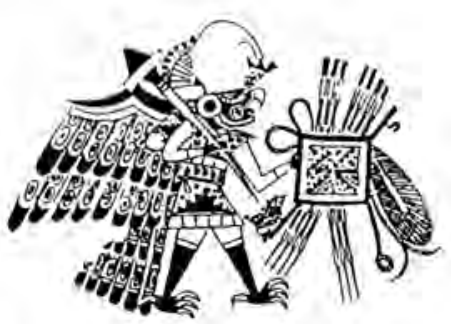

Fig. 93

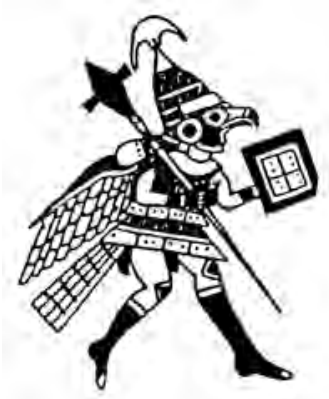

Fig. 96 


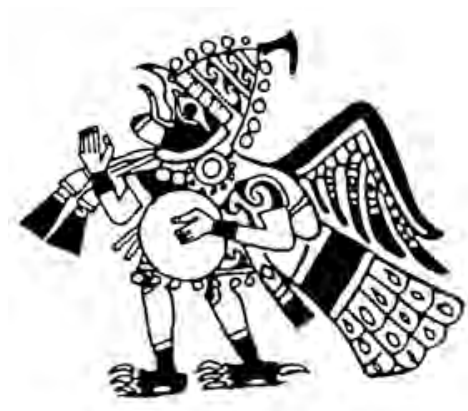

Fig. 97

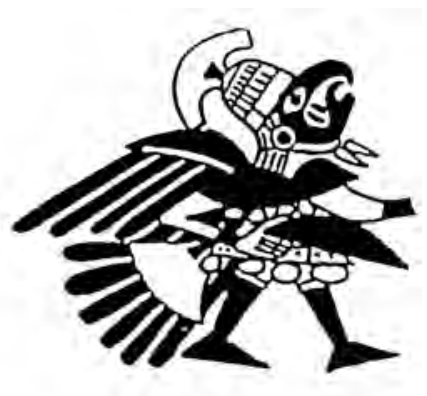

Fig. 98

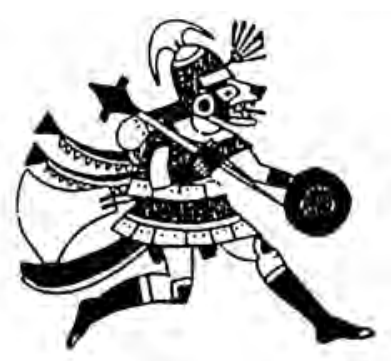

Fig. 99

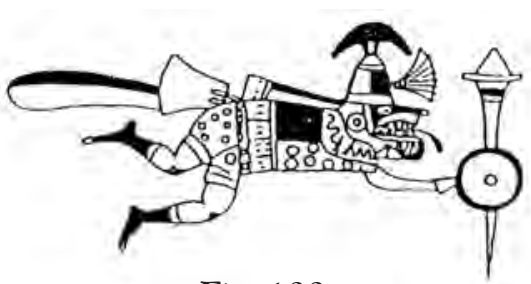

Fig. 100

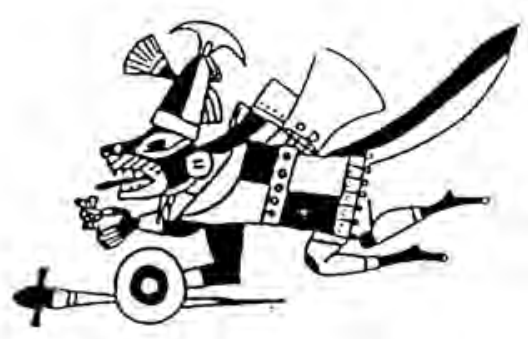

Fig. 102

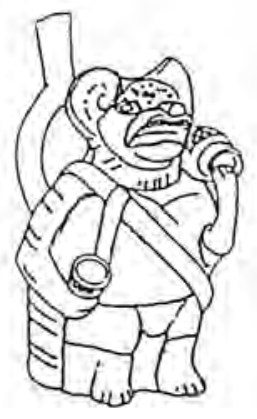

Fig. 104

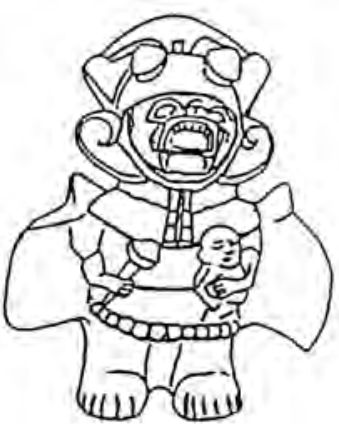

Fig. 105

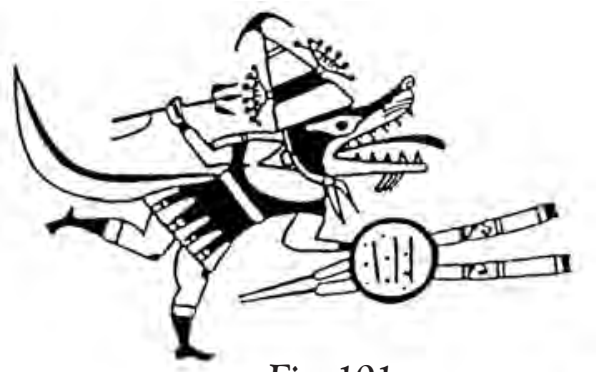

Fig. 101

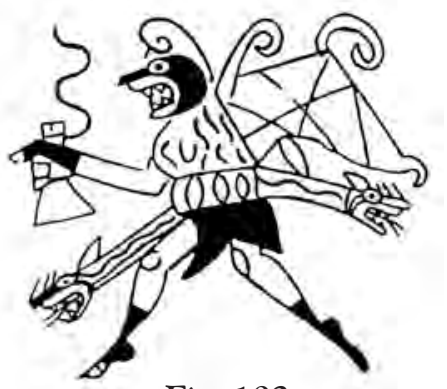

Fig. 103

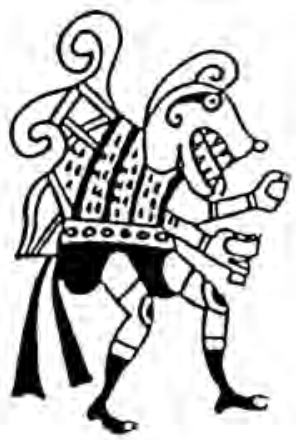

Fig. 106 
Divinidad z-F: La divinidad picaflor.

Rasgos zoomorfos:

Cabeza: Ave con pico muy alargado característico, algunas veces con dientes en el pico. Cuerpo: cola de picaflor, larga y bifurcada, y alas anidadas a cuerpo humaniforme.

\section{Rasgos antropomorfos:}

Cuerpo/extremidades: Antropomorfos.

Tocado: Casco de guerrero con emblema en forma de hacha y turbantes diversos.

Vestimenta: camisa con taparrabo o faldellín.

Requisitos: Frecuentemente porra, escudo, honda y lanzas; a menudo carga un costal.

(Fig. 107-110)

Divinidad z-G: La divinidad ciervo.

Rasgos zoomorfos:

Cabeza: Cabeza de ciervo con astas simples irregulares, orejas en forma de hoja grandes, lengua fuera de la boca, superficie de piel de animal.

Cuerpo: Cola parada añadida a cuerpo humaniforme, también cuerpo cerviforme con superficie de piel.

Rasgos antropomorfos:

Cuerpo: Generalmente antropomorfo.

Extremidades: Siempre antropomorfas.

Tocado: Normalmente sin tocado, algunas veces casco con emblema en forma de hacha.

Vestimenta: Camisa, taparrabo o faldellín.

(Fig. 111-114)

Divinidad z-H: La divinidad cangrejo.

Rasgos zoomorfos:

Cabeza: Ojos redondos u ojos característicos de cangrejo carretero en borde superior de caparazón.

Cuerpo: Caparazón característico de cangrejo carretero en forma triangular, romboide, semicircular o rectangular con dibujo de cara, en el borde inferior se muestra la sección inferior del cuerpo como anexo.

Extremidades: Pinzas y varias parejas de extremidades características de cangrejo.

\section{Rasgos antropomorfos:}

Cabeza: generalmente pequeña cabeza humana con melena en borde superior.

Extremidades: Siempre aparecen piernas antropomorfas.

(Fig. 115-118)

Divinidad z-J: La divinidad culebra.

Rasgos zoomorfos:

Cabeza: Alargada con ojo redondo, lengua bífida entre hileras de dientes, orejas atípicas de serpiente.

Cuerpo: De culebra, compactado, fuertemente ondulado y de cola en punta; dibujo de tréboles en superficie.

Rasgos antropomorfos:

Extremidades: Un brazo y una pierna antropomorfa.

Requisitos: Porra y escudo en brazo antropomorfo.

(Fig. 119-122)

Divinidad $z-\mathrm{K}$ : La divinidad águila.

Rasgos zoomorfos:

Cabeza: De ave con pico aguileño alargado, de vez en cuando con dentadura felínica, cresta de plumas.

Cuerpo: Cuerpo achatado con alas cuyas plumas están redondeadas, cola con alrededor de cinco plumas que muestran puntas claras.

Extremidades: Mayormente garras típicas .

Rasgos antropomorfos:

Extremidades: Raras veces extremidades antropomorfas.

Vestimenta:

Atributos/requisitos: Casi siempre se presenta con vaso en forma de campana.

(Fig. 123-126)

III. Divinidades híbridas

Divinidad h-A: La divinidad monstruo strombus. 


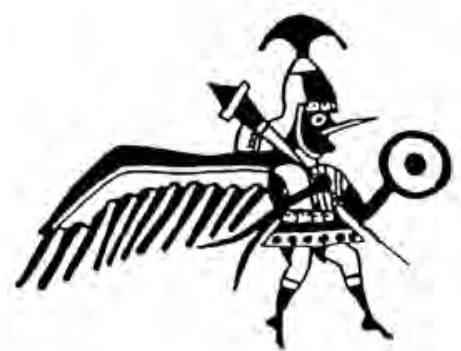

Fig. 107

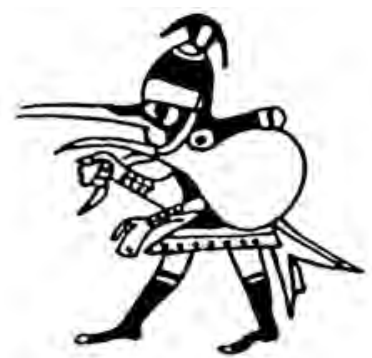

Fig. 110

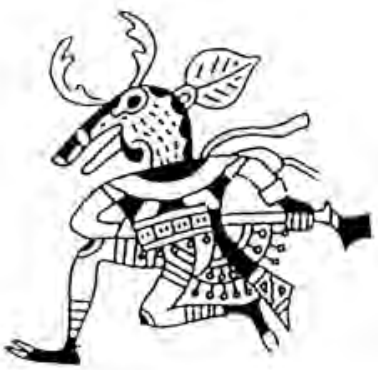

Fig. 113

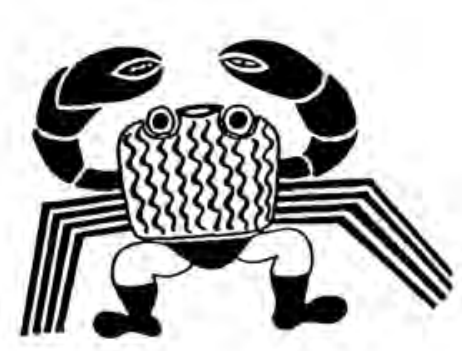

Fig. 116

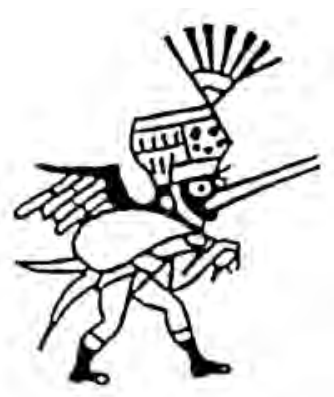

Fig. 108
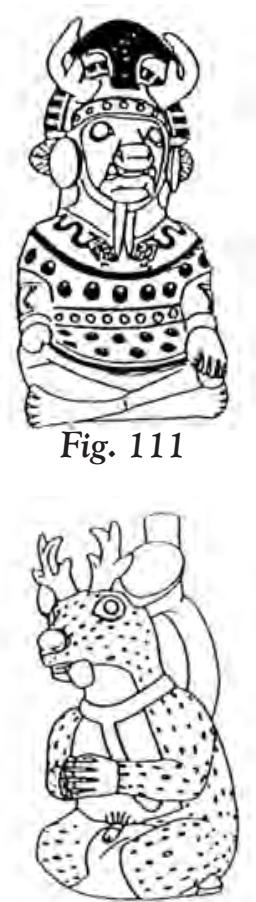

Fig. 114

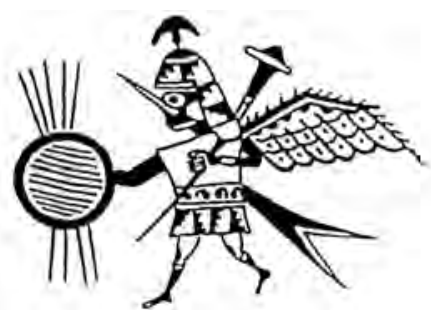

Fig. 109

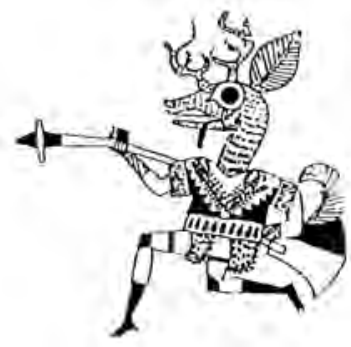

Fig. 112

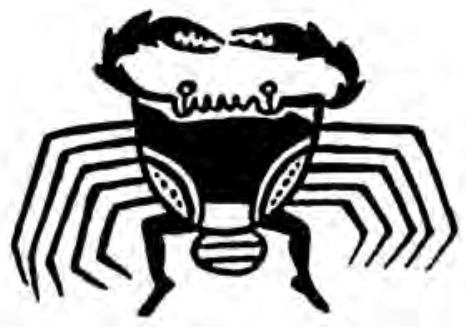

Fig. 115

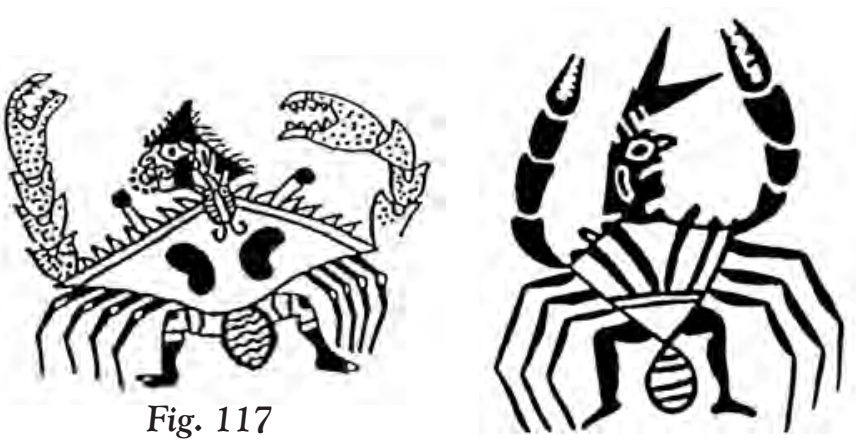

Fig. 118 


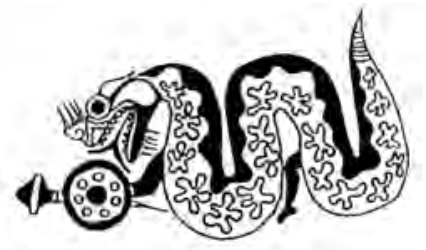

Fig. 119

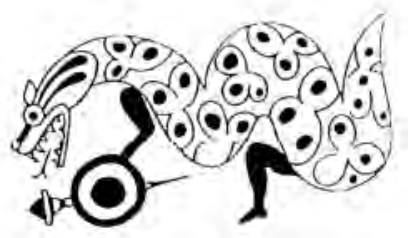

Fig. 120

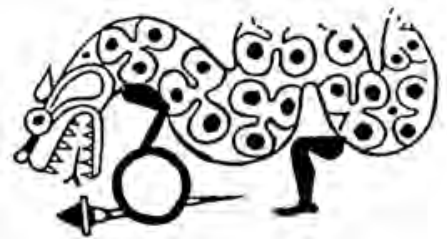

Fig. 121

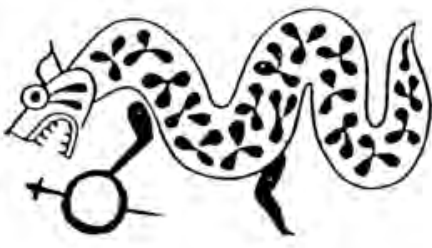

Fig. 122

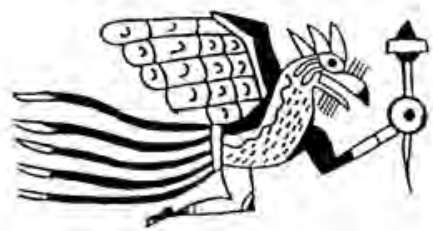

Fig. 123

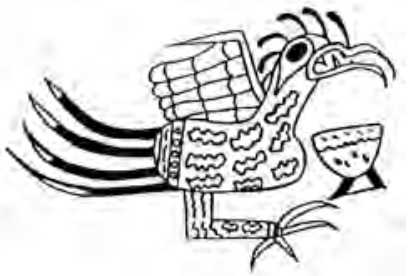

Fig. 126

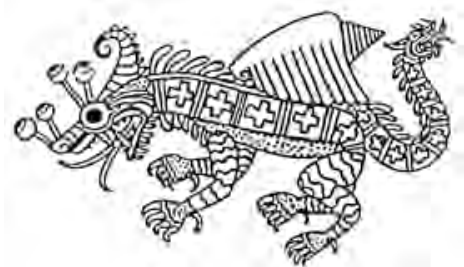

Fig. 129

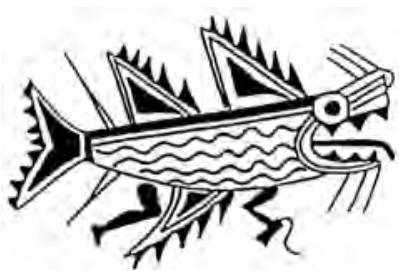

Fig. 132

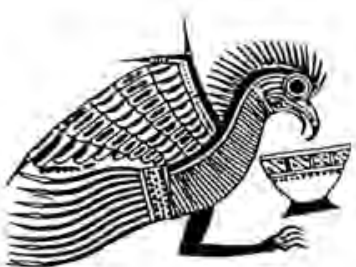

Fig. 124

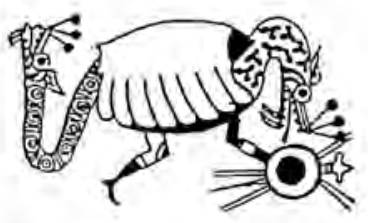

Fig. 127

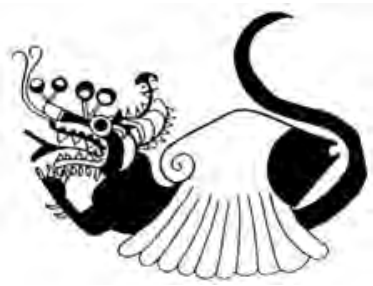

Fig. 130

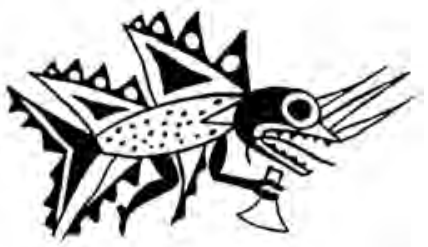

Fig. 133

Fig. 131 


\section{Rasgos zoomorfos:}

Cabeza: Alargada, felínica, con fauces felínicas y lengua bífida, orejas curvadas hacia adelante, dos, tres o cuatro antenas de caracol en la superficie del hocico.

Cuerpo: Alargado, frecuentemente con cresta dentada, con dibujos variados, como manchas de jaguar, líneas onduladas o elementos cuadrangulares, la punta de la cola aparece algunas veces con versión menor de la cabeza.

Extremidades: Cuatro patas con garras.

\section{Rasgos antropomorfos:}

Extremidades: muy raras veces las patas han sido sustituidas por extremidades antropomorfas.

Atributos: La divinidad es caracterizada por el caracol strombus que cubre su cuerpo parcialmente, de tamaño variado. Siempre es reconocible como caracol, tanto por la punta en espiral como por la abertura que se abre en forma de ala seccionada.

(Fig. 127-130)

Divinidad h-B: La divinidad monstruo pez.

\section{Rasgos zoomorfos:}

Cabeza: Ojo grande y redondo, fauces abiertas con dientes pronunciados, lengua grande que sale.

Cuerpo: Con aletas grandes y dentadas, dorsales, ventrales y de cola; frecuentemente púas grandes que salen de la cola; dibujo en la superficie muy variado, punteado, ondulado, escamoso, o lineal.

\section{Rasgos antropomorfos:}

Extremidades: Siempre aparece en la parte inferior un brazo humano, algunas veces un brazo y una pierna antropomorfos.

(Fig. 131-134)

Divinidad h-C: La divinidad con aletas y mechones.

\section{Rasgos zoomorfos:}

Cabeza: De animal rapaz, siempre con hocico grande con hileras de dientes, frecuentemen- te con lengua larga que cuelga hacia afuera. Característico es el pelo con dos mechones largos, representado de maneras diversas, el largo de los mechones puede ser como el cuerpo, y éstos pueden terminar en cabezas de animales o terminar en punta; algunas veces son enrollados como volutas. $\bigcirc$ también el pelo es representado como peine dentado. Cuerpo: Una o dos pares de aletas añada lateralmente al cuerpo antropomorfo; las aletas varían en forma, triangulares, en forma de espinas de tamaño muy irregular; algunas veces muestra cola de pez.

\section{Rasgos antropomorfos:}

Cuerpo/extremidades: Antropomorfos.

Vestimenta: Camisa a cuadros o de rayas verticales y taparrabo.

Requisitos: Hacha y frecuentemente cabeza trofeo.

(Fig. 135-138)

Divinidad h-D: La divinidad en forma de animal rapaz con la cabeza dirigida hacia atrás y la cresta.

\section{Rasgos zoomorfos:}

Cabeza: Ojos grandes, orejas grandes, fauces abiertas dentadas, tres o cuatro púas ligeramente curvas; lengua que sale del hocico; la cabeza siempre aparece mirando para atrás. Cuerpo: Espalda y cola con cresta dentada; dibujo variado sobre cuerpo, círculos, líneas onduladas, manchas de jaguar, puntas, la cola termina frecuentemente en cabeza menor del mismo tipo.

Extremidades: Cuatro patas con garras.

\section{(Fig. 139-142)}

Divinidad h-E: La divinidad con el anexo de la cola llena de peces.

Rasgos zoomorfos:

Cabeza: Mayormente con características de animal con hocico con hilera de dientes, el pelo en mechón liso, ondulado o crespo.

Cuerpo: Añadido al cuerpo antropomorfo a 


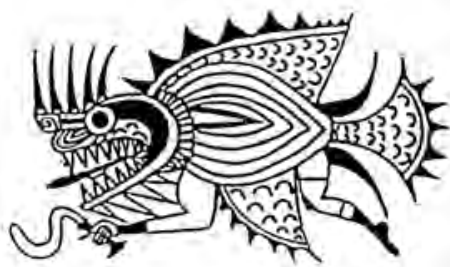

Fig. 134

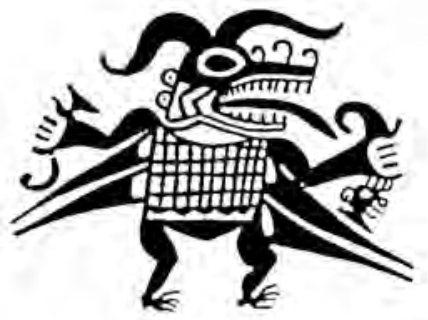

Fig. 135

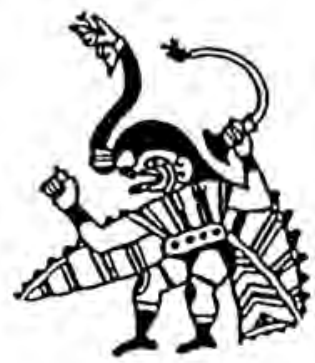

Fig. 137

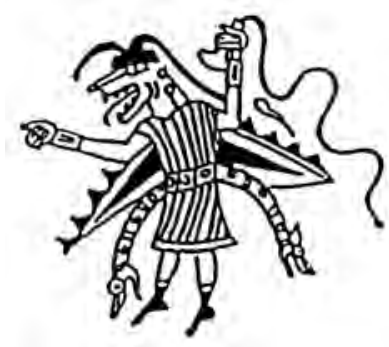

Fig. 138

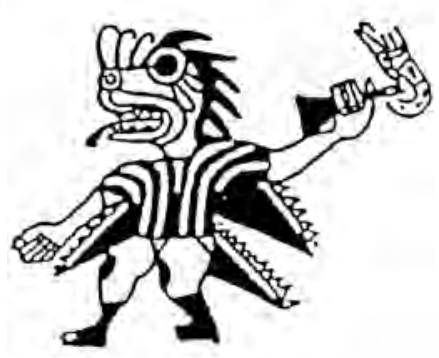

Fig. 136

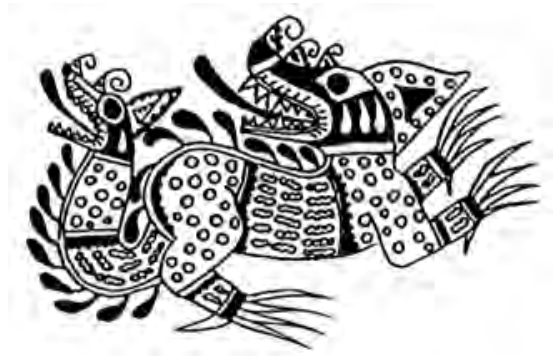

Fig. 139

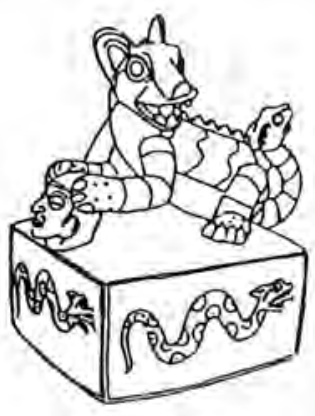

Fig. 140

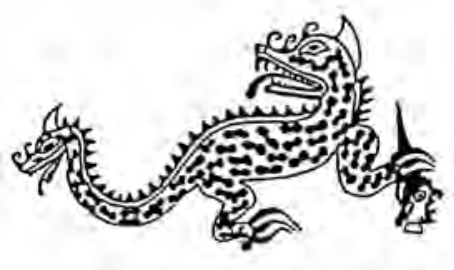

Fig. 141

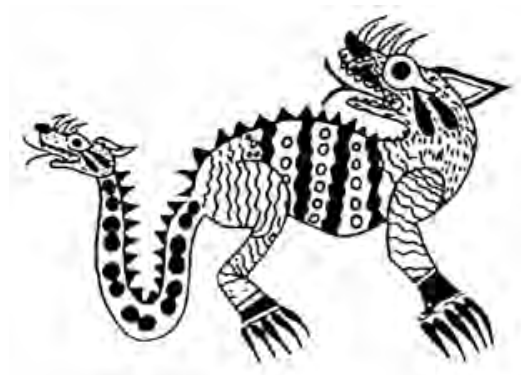

Fig. 142

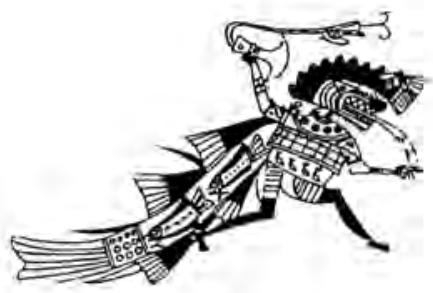

Fig. 143

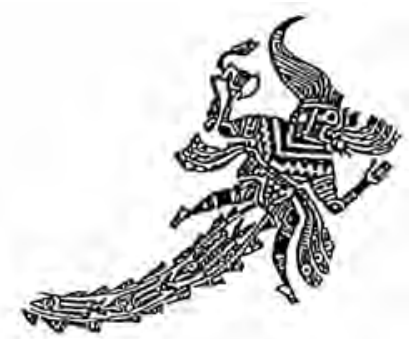

Fig. 144

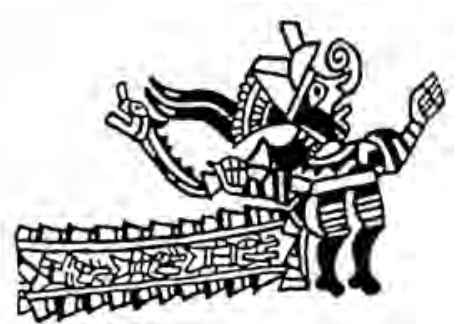

Fig. 145 


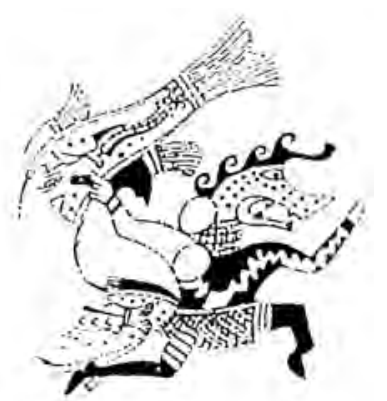

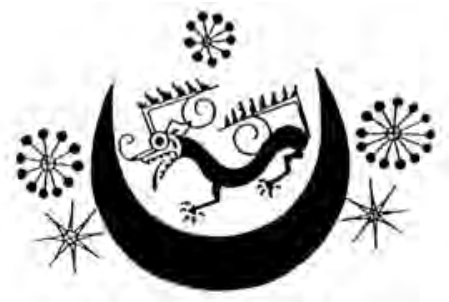

Fig. 147

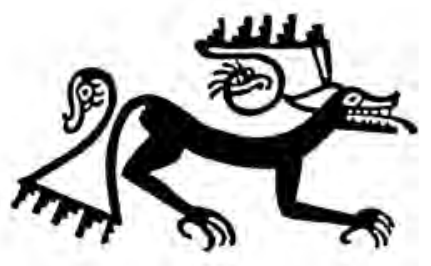

Fig. 148

Fig. 146

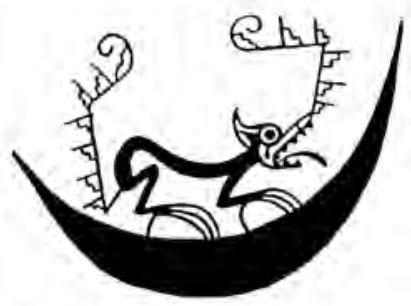

Fig. 149

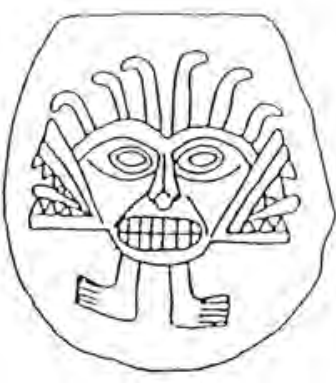

Fig. 152

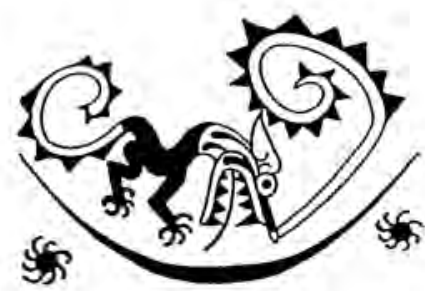

Fig. 150

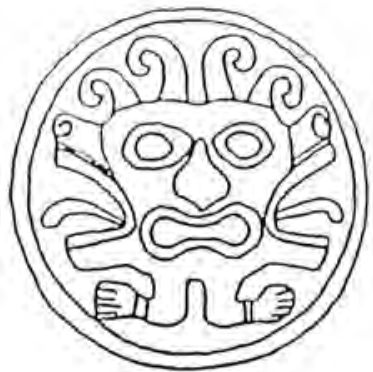

Fig. 151

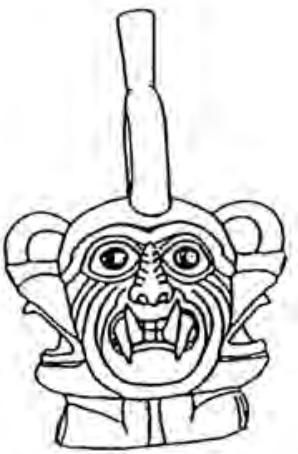

Fig. 154

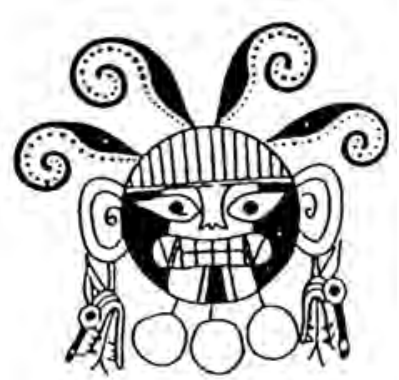

Fig. 155

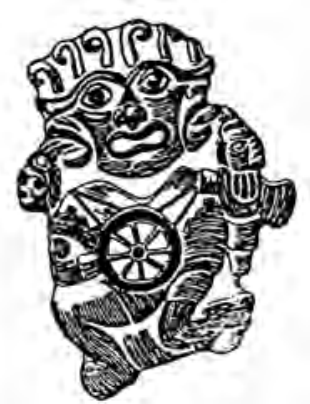

Fig. 153

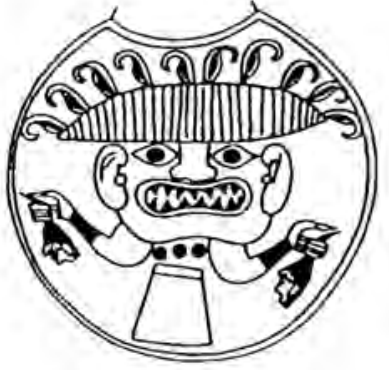

Fig. 156

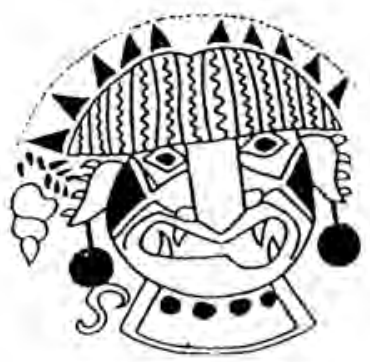

Fig. 157 
la altura de las caderas un anexo en forma de cola, al interior de ésta hay varios peces menores en fila.

Rasgos antropomorfos:

Cabeza: Algunas veces antropomorfa.

Cuerpo/extremidades: Antropomorfos.

Vestimenta: Camisa y taparrabo.

Requisitos: Hacha.

(Fig. 143-146)

Divinidad h-F: La divinidad animal rapaz con el anexo lleno de adornos de escalera.

\section{Rasgos zoomorfos:}

Cabeza: De animal rapaz, con ojo grande y redondo, oreja en punta, hocico grande con hilera de dientes y lengua saliente. $\mathrm{Ca}$ racterístico de esta divinidad es un anexo anular en la cabeza, adornado con escaleras y volutas.

Cuerpo: Serpenteante, frecuentemente con otro elemento angular adornado en vez de cola.

Extremidades: Patas con garras.

Atributos: El ser frecuentemente se presenta al interior de una luna creciente muy delgada, acompañada de estrellas estilizadas.

(Fig. 147-150)

Divinidad h-G: La divinidad de las tres caras.

\section{Rasgos zoomorfos:}

Cabeza: Dividida en tres caras, la central vista de frente con ojos, nariz y boca de dentadura felínica con volutas a manera de pelo, las dos laterales de perfil con características de hocico animal; la cara central humaniforme.

Cuerpo: Por lo general sólo se representa como cabeza.

\section{Rasgos antropomorfos:}

Cuerpo/extremidades: Raras veces con cuerpo, entonces antropomorfo; en este caso las cabezas laterales muestran indicios de extremidades humanas.

(Fig. 151-154)
Divinidad h-H: La divinidad con la cara frontal y el gorro de mechones.

Rasgos antropomorfos:

Cabeza: Este ser solo aparece como cabeza; ojos, orejas, nariz y boca antropomorfos.

Tocado: No es claramente distinguible si se trata de tocado o pelo, con rayas verticales, en el borde superior volutas o dientes.

Extremidades: Muy raro que se añada brazos humanos.

Adorno: Frecuentemente aparece con collar de perlas.

Rasgos zoomorfos:

Cabeza: Fauces felínicas.

(Fig. 155-158)

Divinidad h-J: La divinidad con la cara compuesta.

Rasgos antropomorfos:

Cabeza: El ser sólo se presenta como cabeza, la cara muestra con ojos, orejas, nariz y boca un cierto aire antropomorfo; ranuras profundas dan aspecto de vejez, los ojos aparecen como encerrados por un antifaz.

Adorno: orejera en forma de cabeza de serpiente.

Rasgos zoomorfos:

Cabeza: Fauces felínicas.

Atributos: Parte posterior de la cabeza esta compuesta de lobo de mar, lechuza y pez.

(Fig. 159-161)

Divinidad h-K: La divinidad animal rapaz con caracol.

Rasgos zoomorfos:

Cabeza: Con características de animal rapaz, con ojo grande y redondo, oreja puntiaguda, hocico dentado y frecuentemente lengua bífida.

Cuerpo: De caracol, algunas veces con cuerpo de animales rapaces y cola larga.

Extremidades: Sólo cuando tiene cuerpo de cuadrúpedo muestra garras.

Atributos: Caracol en forma de cono añadido al cuerpo.

(Fig. 162-165) 
Divinidad h-L: La divinidad en forma de bola.

Rasgos antropomorfos:

Cabeza: Antropomorfa.

Tocado: Casquete con divisa semilunar algunas veces con dos bandas, abanico de plumas, frecuentemente colgando sobre el dorso dos bandas largas dentadas.

Extremidades: Antropomorfas.

Rasgos zoomorfos:

Cabeza: Fauces felínicas con comisuras esquinadas.

Rasgos no definibles: Lo característico de este personaje es su cuerpo globular, adornado con círculos pequeños.

(Fig. 166-169)

\section{Divinidades fitomorfas}

Divinidad p-A: La divinidad frijol.

Rasgos antropomorfos:

Cabeza: La cara insertada al frijol tiene rasgos antropomorfos.

Tocado: Parte superior del caracol con hacha y abanicos de plumas sobrepuestas.

Extremidades: Antropomorfas.

\section{Rasgos fitomorfos:}

Cuerpo: De frijol con pinturas de superficie variadas.

Requisitos: Por lo general sostiene una porra, otros tienen palos de juego.

(Fig. 170-173)

Divinidad p-B: La divinidad mazorca.

\section{Rasgos antropomorfos:}

Cabeza/tocado: Formado por la parte superior de una mazorca la cabeza tiene con ojos, orejas, nariz y boca una cara antropomorfa, cabeza en forma de cono o cono con borde de perlas.

Extremidades: Brazos antropomorfos.

Rasgos zoomorfos:

Cabeza: Fauces felínicas.

Rasgos fitomorfos: El cuerpo está formado por una o varias mazorcas, la superficie aparece graneada.

(Fig. 174-176)
V. Divinidades en forma de objeto

Divinidad o-A: La divinidad macana.

Rasgos antropomorfos:

Cabeza: Cabeza de porra con rasgos antropomorfos.

Tocado: Casco de guerrero, con borde de sombrero formado por el anillo de la porra, hacha sobrepuesta al casco con abanicos de plumas por ambos lados, bandas dentadas que caen del protector de la nuca del casco. Cuerpo: Frecuentemente todo el cuerpo es antropomorfo, con la parte inferior de la macana entre las extremidades.

Extremidades: Brazos y piernas antropomorfas. Vestimenta: Camisa y faldellín, frecuentemente se añade un protector coxal.

Rasgos de objeto: Cuerpo: por lo normal un escudo redondo o rectangular o un disco se juntan a la porra para formar una especie de cuerpo.

(Fig. 177-180)

\section{FUENTES DE LAS ILUSTRACIONES}

1 Kutscher, 1950: Abb. 62

2 Kutscher,1983: Abb. 303-2

3 Kutscher, 1950: Abb. 43

4 Donnan y McClelland, 1999: Fig. 4.103

5 Kutscher, 1950: Abb. 62

6 Kutscher, 1983: Abb. 304

7 Donnan y McClelland, 1999: Fig.4.80

8 Bonavia, 1994: Fot. 214

9 Berezkin, 1983: Fig. 32

10 Donnan y McClelland, 1979: Fig.7

11 McClelland, 1990: Fig. 7

12 Kutscher, 1983: Abb. 318B

13 McClelland, 1990: Fig. 3

14 Kutscher, 1983: Abb. 319

15 Donnan y McClelland, 1999: Fig. 5.66

16 Kutscher,1983: Abb. 194

17 Donnan y McClelland, 1999: Fig. 5.66

18 Kutscher, 1983: Abb. 250

19 Vergara Montero, 1996: Lám. 91

20 Gallardo et al., 1990: Fig. 51*

21 Leicht, 1944: Abb. 211a* 


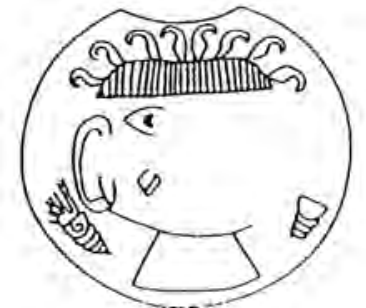

Fig. 158

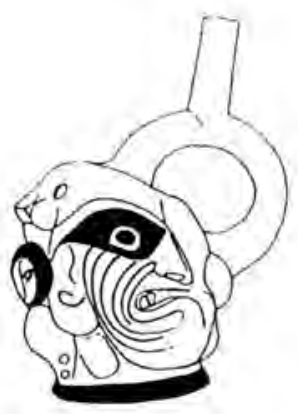

Fig. 161

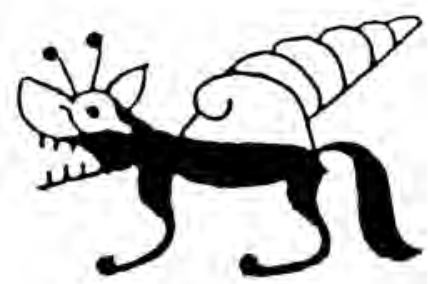

Fig. 164

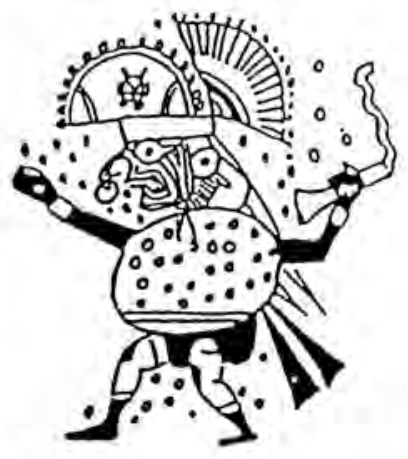

Fig. 167

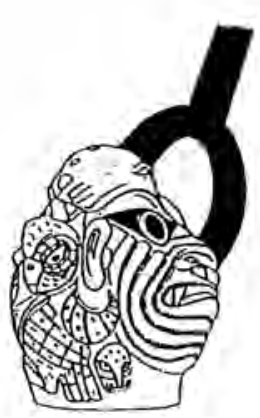

Fig. 159

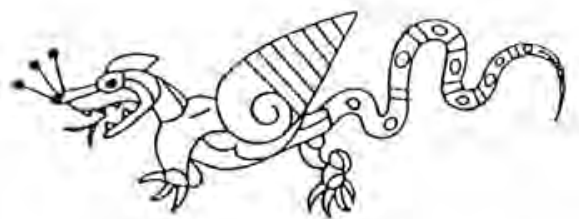

Fig. 162

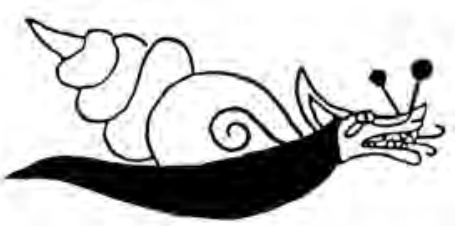

Fig. 165

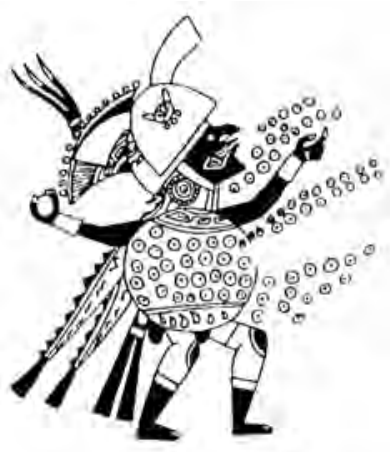

Fig. 168

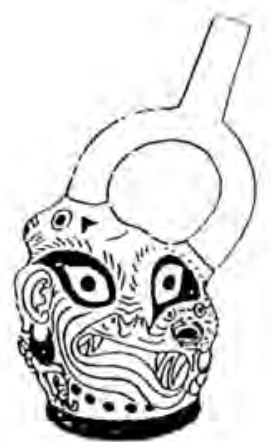

Fig. 160

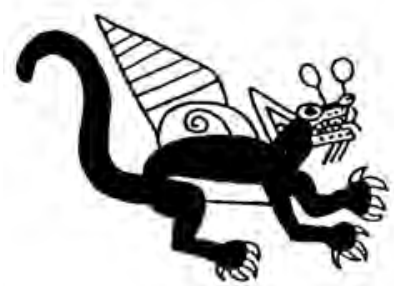

Fig. 163

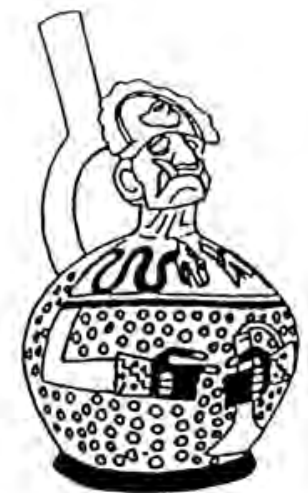

Fig. 166 


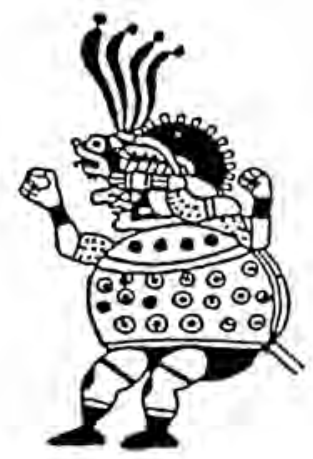

Fig. 169

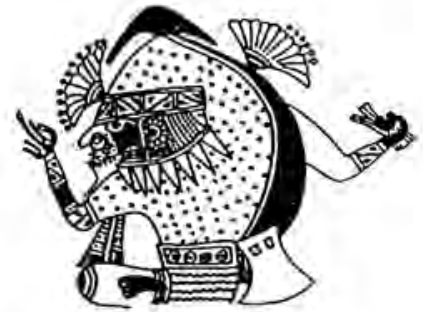

Fig. 172

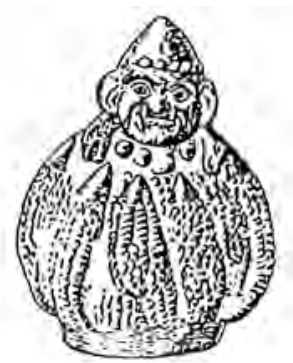

Fig. 175

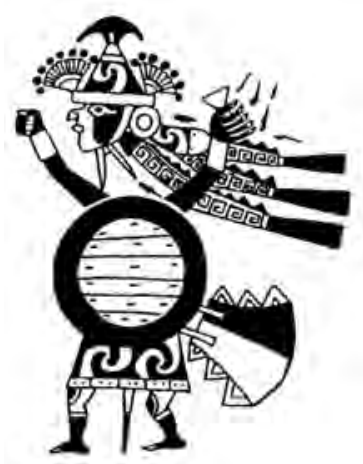

Fig. 178

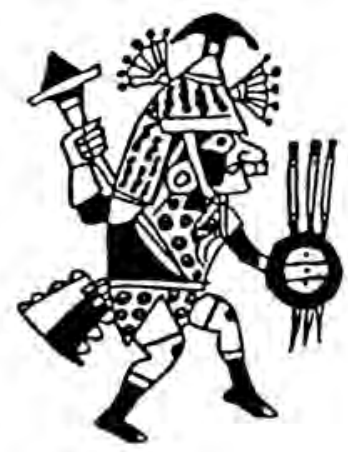

Fig. 170

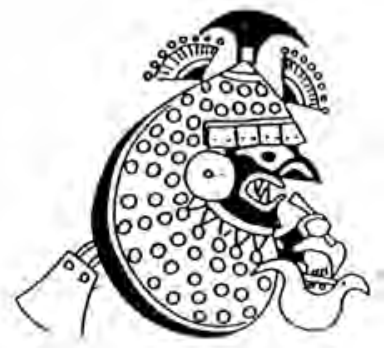

Fig. 173

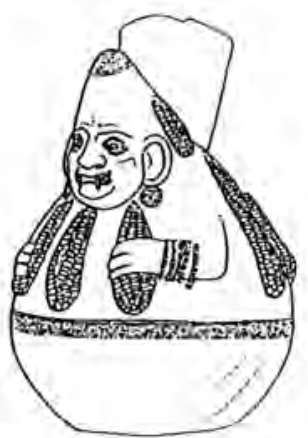

Fig. 176

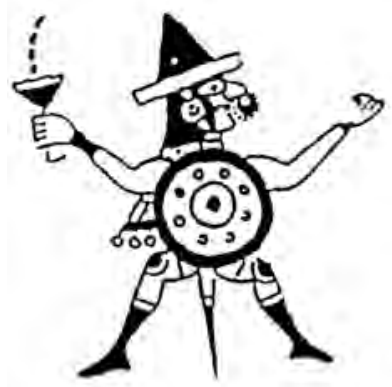

Fig. 179

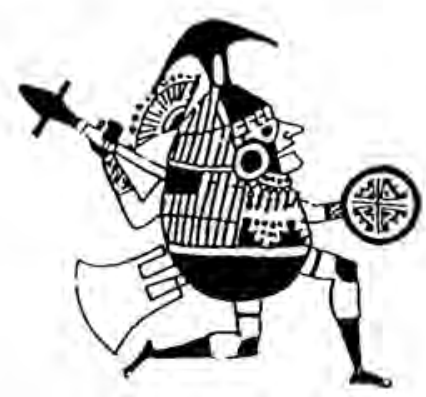

Fig. 171

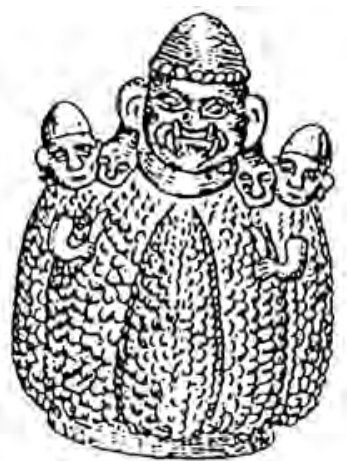

Fig. 174

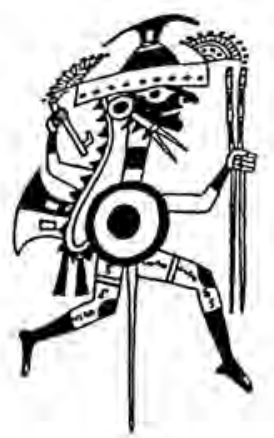

Fig. 177

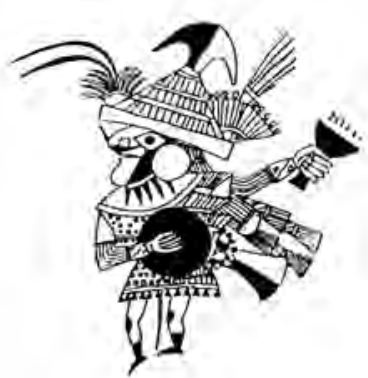

Fig. 180 
22 Kutscher, 1950: Abb. 64

23 Kutscher, 1954: Taf. 60A

24 Museo Nacional Lima (Fot: J. Golte)*

25 Donnan, 1978: Fig. 218*

26 Benson, 1972: Pl. VII*

27 Baessler, 1902/03: Bd. 3, Taf. 89, Fig. 300*

28 Baessler, 1902/03: Bd. 3, Taf. 123, Fig. 354*

29 Fuhrmann, 1922a: Taf. 33*

30 Baessler, 1902/03: Bd. 3, Taf. 110, Fig. 335*

31 Villaret, 1978: 69*

32 Benson, 1972: Ill. 2-7*

33a Baessler, 1902/03: Bd. 3. Taf. 91, Fig. 303*

33b Baessler, 1902/03: Bd. 3, Taf. 91, Fig. 303a*

34 Benson, 1972 : Ill, 2-4*

35 de Lavalle, 1985: 84

36 Kutscher, 1950: Abb. 64

37 Donnan, 1982b : Fig. 8

38 Kutscher, 1954: Taf. 54B

39 Kutscher, 1983: Abb. 259A

40 Kutscher, 1983: Abb. 255

41 Cuesta Domingo, 1980: Fig. 30/1048

42 Lavalle de, 1985: 55*

43 Vergara Montero, 1996: Lám. 51

44 de Lavalle, 1985: 55*

45 Kutscher, 1983: Abb. 246

46 Vergara Montero, 1996: Lám. 95

47 Kutscher, 1954: Taf. 65B

48 Kutscher 1954: Taf. 55C

49 Donnan y McCelland, 1999: 111

50 Kutscher,1983: Abb. 247

51 Della Santa, 1974: Fig. 28

52 Lehmann, 1924: Abb. 18

53 Kutscher, 1983: Abb. 231

54 Kutscher, 1983: Abb. 308

55 Kutscher, 1954: Taf. 64A

56 Kutscher, 1954: Taf. 64B

57 Kutscher, 1954: Taf. 74

58 Donnan, 1978: Fig. 234*

59 Zebhauser, 1996: 63*

60 Wassermann-San Blas, 1938: Fig. 540*

61 Kutscher, 1950: Taf. 63a*

62 Baessler, 1902/03: Bd. 3, Taf. 84, Fig. 287*
63 Alva y Donnan, 1993: Fig. 152

64 Exposición "Sipán”, Maguncia 1992*

65 Alva y Donnan, 1993: Fig. 152

66 Lumbreras, 1979: Lám. 169*

67 Ubbelohde-Doering, 1952: Abb. 172/173*

68 Donnan y McCelland, 1999: Fig. 4.90

69 Kutscher, 1983: Abb. 125

70 Lavalle de, 1990: Fig. 19

71 Donnan y McClelland, 1979 : Fig. 3

72 Donnan y McClelland, 1979 : Fig. 7

73 Donnan y McClelland, 1979 : Fig. 10

74 Lavallée et al., 1999 : Fig. 39

75 Benson, 1982 : Fig. 11

76 Donnan, 1982a : Fig. 8

77 Baessler, 1902/03: Bd. 3, Taf. 88, Fig. 297*

78 Baessler, 1902/03: Bd. 3, Taf. 87, Fig. 295*

79 Berrin, 1997: Fig. 90*

80 Moser, 1974: 36*

81 Schulze-Thulin, 1974: Fig. 41*

82 Bonavia, 1994: Fot. 83*

83 Bird et al., 1981: 39*

84 Donnan, 1978 : Fig. 256*

85 Purin et al., 1992 : Abb. 132*

86 Baessler, 1902/03 : Bd. 3, Taf. 121, Fig. $350 *$

87 Donnan y McClelland, 1999: Fig. 3.22

88 Kutscher, 1950: Abb. 64

89 Donnan y McClelland, 1999: Fig. 4.95

90 Kutscher, (archivo): Original en Museum für Völkerkunde München Nr. 13

91 Baessler, 1902/03: Bd. 3, Taf. 52, Fig. 222*

92 Sawyer, 1966: Fig. 64

93 Donnan y McClelland, 1999: Fig. 4.26

94 Baessler, 1902/03: Bd. 2, Taf. 51, Fig. 220*

95 Kutscher, 1983: Abb. 188

96 Kutscher, 1950: Abb. 37

97 Berrin, 1997: 165

98 Kutscher, 1983: Abb. 303-2

99 Kutscher, 1950: Abb. 37

100 Vergara Montero, 1996: Lám.66

101 Kutscher, 1983: Abb. 165

102 Kutscher, 1983: Abb. 172 
103 Kutscher, 1983: Abb. 218

104 Benson, 1972: Fig. 3-23*

105 Anders, 1983: Kat. Nr. 7.23*

106 Kutscher, 1983: Abb. 304

107 de Bock, 1988: Fig. 2

108 Kutscher, 1950 : Abb. 43

109 Kutscher, 1983: Abb. 183

110 Donnan, 1978: Fig. 113

111 Anton, 1962: Taf. 64*

112 Berrin, 1997: Fig. 14

113 Vergara Montero, 1996: Lám. 75

114 Lothrop, 1980: 182*

115 Kutscher, 1954: Taf. 10 A

116 Museo Amano, 1981: 88

117 Kutscher, 1983: Abb. 262 A

118 Kutscher, 1954: Taf. 57 B

119Lavallée, 1970: Pl. 77 A

120 Kutscher 1983: Abb. 224

121 Kutscher, 1954 : Taf. 41 A

122 Kutscher, 1954: Taf. $41 \mathrm{C}$

123 Kutscher, 1983: Abb. 177

124 Kutscher, 1983: Abb. 199

125 Jiménez Borja, 1938: 33

126 Kutscher, 1983: Abb. 197

127 Leicht, 1944:22

128 Ubbelohde-Doering, 1926: Abb. 21

129 Kutscher, 1983: Abb. 45

130 Kutscher, 1983: Abb. 38

131 Cuesta Domingo, 1980: Fig. 27/1007

132 Kutscher, 1954: Taf. 51 A

133 Kutscher, 1983: Abb. 251

134 Kutscher, 1983: Abb. 255

135 Vergara Montero, 1996: Lám. 80

136 Berrin, 1997: 145

137 Kutscher, 1954: Taf. 54 B

138 Della Santa, 1974: Fig. 27

139 Lavallée, 1970: Pl. 64

140 Lothrop, 1980: 73*

141 Kutscher, 1983 : Abb. 10

142 Della Santa, 1974 : Fig. 23

143 de Lavalle, 1985: 62

144 Donnan, 1979: Fig. 37
145 Kutscher, Nachlaß : "Muelle 1949-50: 277"

146 Vergara Montero, 1996: Lám. 65

147 Kutscher, 1954: Taf. 44B

148 Kutscher, 1983: Abb. 310

149 Kutscher, 1983: Abb. 309 A

150 Kutscher, 1983: Abb. 313

151 Parsons, 1980: Fig. 420*

152 Schmidt, 1929: 386*

153 Berezkin, 1983: Fig. 40

154 Kutscher, 1950: Taf. 66*

155 Wassermann-San Blas, 1938: Titelblatt

156 Kutscher, 1983: Abb. 223

157 Vergara Montero, 1996: Lám. 126

158Donnan, 1985: Fig. 10

159 Schmidt, 1929: 166*

160 Kutscher, 1950: Taf. 74*

161 Heydrich et al., 1959: Taf. 34*

162 Vergara Montero, 1996: Lám. 42

163 Kutscher, 1983: Abb. 32

164 Vergara Montero, 1996: Lám. 31

165 Kutscher, 1983: Abb. 29

166 Larco Hoyle, 1945: 22*

167 Cuesta Domingo, 1980: Fig. 29/1043

168 Kutscher, 1983: Abb. 263 A

169 Kutscher, 1954: Taf. 54 B

170 Donnan y McClelland, 1999: Fig. 6.63

171 Berrin, 1997: 58

172 Kutscher, 1983: Abb. 212

173 Kutscher, 1983: Abb. 211

174 Carrión Cachot, 1959: Fig. 83b

175 Carrión Cachot,1959: Fig. 83a

176 Fuhrmann, 1922b: Taf. 25*

177 Larco Hoyle, 1966: Abb. 41*

178 Kutscher, 1983: Abb. 271

179 Kutscher, (Archivo): Original en Museum

für Völkerkunde München Nr. 16

180 Museo Cassinelli, Trujillo/Perú (Foto J. Golte) $*$

El asterisco (*) significa que la fuente muestra un original que ha sido dibujado por la autora. 


\section{BiblografíA}

Alva, Walter et al.

1989 Das Fürstengrab von Sipán. Mainz

Alva, Walter y Christopher Donnan

1993 Royal Tombs of Sipán. Los Angeles

Amano, Yoshitaro

1981 Diseños precolombinos del Perú. Museo Amano. Lima

Anders, Ferdinand et al.

1983 "Peru durch die Jahrtausende. Kunst und Kultur im Landeder Inka". Kata$\log$ des Niederösterreichischen Landesmuseums, Neue Folge, Nr. 133. Wien

Anton, Ferdinand

1962 Alt-Peru und seine Kunst. Leipzig

1977 Alt-Amerika und seine Kunst. Leipzig

Baessler, Arthur

Altperuanische Kunst. Beiträge zur Archäologie des Inca-Reichs, 4 Bde. 1902/03. Berlin, Leipzig

Bankes, George

1977 Peru before Pizarro. Oxford

Benson, Elizabeth

1972 The Mochica. A Culture of Peru. New York, Washington

1982 The Well-Dressed Captives: Some Observations on Moche Iconography. In Baessler-Archiv, Neue Folge, Band 30: 181-222. Berlin

Berezkin, Yuri

1983 Die Zivilisation der Indianer des nördlichen Küstenstreifens von Peru im 1.-7. Jahrhundert. Leningrad (in russischer Sprache)

Berrin, Kathleen (Ed.)

1997 The Spirit of Ancient Peru. Treasures from the Museo Arqueológico Rafael Larco Herrera. San Francisco

Bird, Junius et al.

1981 Museums of the Andes. New York

Bock, Edward de

1988 Moche: Gods, Warriors, Priests. Rijksmuseum voor Volkenkunde, Leiden
Boglár, Lajos und Tamás Kovács

1984 Indianische Kunst von Mexiko bis Peru. Stuttgart

Bonavia, Duccio

1994 Arte e Historia del Perú Antiguo. Col. Enrico Poli Bianchi. Arequipa/Perú

Bounoure, Vincent

1968 Die amerikanische Malerei. Lausanne

Carrión, Rebeca

1959 La religión en el antiguo Perú. Lima

Castillo, Luis Jaime

1989 Personajes míticos, escenas y narraciones en la iconografía mochica.Lima

Cuesta, Mariano

1980 Cultura y cerámica mochica. Museo de América. Madrid

Della Santa, Elizabeth

1974 La collection de vases mochicas des Musées Royaux d'Art et d'Histoire. Bruxelles

Dickey, Thomas et al.

1989 Die Könige von El Dorado. Herrsching

Donnan, Christopher

1976 Moche Art and Iconography. Los Angeles

1978 Moche Art of Peru. Los Angeles

1982a "Dance in Moche Art". En Nawpa Pacha 20: 97-120. Berkeley

1982b "La caza del venado en el arte mochica". En Revista del Museo Nacional, Tomo XLVI: 235-251. Lima

1985 Archaeological Confirmation of a Moche Ceremony. En Indiana 10: 371 . 381. Berlin

Donnan, Christopher B. and Donna McClelland

1979 "The Burial Theme in Moche Iconography". Studies in Pre-Columbian Art and Archaeology, Number TwentyOne.

Moche Fineline Painting. Its Evolution and Ist 1999 Artists. Los Angeles 


\section{DUMBARTON Oaks}

Trustees for Harvard University. Washington, D.C.

Fuhrmann, Ernst

1922a Reich der Inka. Hagen i.W.

1922b Peru II. Hagen i.W., Darmstadt

Gallardo, Francisco et al.

1990 Moche. Señores de la muerte. Santiago de Chile

Heydrich, Martin et al.

1976 Schätze aus Peru. Von Chavin bis zu den Inka. Rautenstrauch-Joest-Museum, Köln

Hocquenghem, Anne Marie

1983 Iconografía Moche. LateinamerikaInstitut der Freien Universität Berlin

1987 Iconografía Mochica. Lima

Jiménez Borja, Arturo

1938 Moche. Lima

Kauffmann, Federico:

1978 Manual de arqueología peruana. Lima

1979 Sexualverhalten im Alten Peru. Lima KETTERER

1987 Auktionskatalog 119. München

Klein, Otto

1967 La cerámica mochica. Caracteres, estilísticos y conceptos. Valparaíso

Kosok, Paul

1965 Life, Land and Water in Ancient Peru. New York

Kutscher, Gerdt

1950 Chimu. Eine altindianische Hochkultur. Berlin

1954 Nordperuanische Keramik. Figürlich verzierte Gefäße der Früh-Chimu. Berlin

1958 "Ceremonial "Badminton" in the Ancient Culture of Moche (North Peru)". En Proceedings of the XXXII International Congress of Americanists, Copenhagen 1956: 422-432. Copenhagen

1983 Nordperuanische Gefäßmalereien des Moche-Stils. Mit einer Einführung und Nachweisen von Ulf Bankmann. München

Larco Hoyle, Rafael

1938 Los Mochicas. Tomo I. Lima

1939 Los Mochicas. Tomo II. Lima

1945 Los Mochicas. Peru

1948 Cronología arqueológica del norte del Perú. Buenos Aires

1966 Peru. München, Genf, Paris

Lavalle, José Antonio de (Ed.)

1985 Moche. Arte y tesoros del Perú. Lima

1990 Lambayeque. Lima

Lavallée, Danièle

1970 Les représentations animales dans la céramique mochica. Université de Paris. Mémoires de l'Institut d'Ethnologie IV. Paris

Lavallée, Danièle et al.

1999 Perú - dioses, pueblos y tradiciones. Finistère

Lehmann, Walter

1924 Kunstgeschichte des alten Peru. Berlin Leicht, Hermann

1944 Indianische Kunst und Kultur. Ein Jahrtausend im Reiche der Chimu. Zürich

Lieske, Bärbel

1992 Mythische Erzählungen in den Gefäßmalereien der altperuanischen MocheKultur. Bonn

Lothrop, Samuel K.

1980 Azteken - Maya - Inka. Stuttgart

Lumbreras, Luis Guillermo

1979 El arte y la vida Vicús. Lima

Makowski, Krzysztof

1996 "Los Seres Radiantes, el Águila y el Búho”. En Imágenes y Mitos. Ensayos sobre las Artes Figurativas en los Andes prehispánicos. Lima

McClelland, Donna D.

1977 "The Ulluchu. A Moche Symbolic Fruit". En Cordy-Collins, Alana and Jean Stern (Eds.): Pre-Columbian Art History. Selected Readings: 435-452. Palo Alto 
1990 "A Maritime Passage from Moche to Chimu". En Moseley, M./A. CordyCollins (Eds.): The Northern Dynasties: Kingship and Statecraft in Chimor. Washington, D.C.

Menzel, Dorothy

1977 The Archaeology of Ancient Peru and the Work of Max Uhle. Berkeley

Moseley, Michael

1992 The Incas and their Ancestors. The Archaeology of Peru. London

Moser, Christopher

1974 "Ritual Decapitation in Moche Art". En Archaeology, Vol. 27, No. 1: 30-37. New York

Mujica Gallo, Miguel et al.

1962 Lor du Pérou. Trésors de l'empire Inca. Katalog Bruxelles

Parsons, Lee

1980 Pre-Columbian Art. The Morton D. May and the Saint Louis Art Museum Collections. New York

Purin, Sergio et al.

1992 Inka Peru. Tübingen

Sawyer, Alan

1954 The Nathan Cummings Collection of Ancient Peruvian Art. Art Institute of Chicago

1966 Ancient Peruvian Ceramics. The $\mathrm{Na}$ than Cummings Collection. The Metropolitan Museum of Art, New York

1968 Mastercraftsmen of Ancient Peru. The Solomon R. Guggenheim Museum New York

Schmidt, Max

1929 Kunst und Kultur von Peru. Berlin Schulze-Thulin, Axel

1974 Im Zeichen des Jaguars. Indianische Frühkulturen in Alt-Peru. Bildheft 1 des Linden-Museums Stuttgart
Shimada, Izumi

1978 "Economy of a Prehistoric Urban Context: Commodity and Labor Flow at Moche V Pampa Grande, Peru". En American Antiquity, Vol. 43, No. 4: 569-592. Menasha

Stierlin, Henry

1983 Die Kunst der Inka und ihrer Vorläufer. Stuttgart, Zürich

Ubbelohde-Doering, Heinrich

1926 Altperuanische Gefäßmalereien. 1. Teil. Marburg

1952 Kunst im Reiche der Inca. Tübingen

Urteaga-Ballón, Oscar

1968 Interpretación de la sexualidad en la cerámica del antiguo Perú. Lima

Vergara, Enrique et al.

1996 Mitografía Mochica. Trujillo

Villaret, Bernard

1978 Art ancien du Pérou. Papeete, Tahiti

Wassermann-San Blas, B. J.

1938 Cerámicas del Antiguo Perú de la Colección Wassermann-San Blas. Buenos Aires

Wurster, Wolfgang W.

1991 Die Schatzgräber. Archäologische Expeditionen durch die Hochkulturen Südamerikas. Hamburg

Zebhauser, Helmuth und Maike Trentin-Meyer (Hg.)

1996 Das Alpine Museum des Deutschen Alpenvereins. Katalog. München 